СОВРЕМЕННОЕ СОСТОЯНИЕ ИССЛЕДОВАНИЙ В ОБЛАСТИ ОЖИРЕНИЯ: ГЕНЕТИЧЕСКИЕ АСПЕКТЫ, РОЛЬ МИКРОБИОМА И ПРЕДРАСПОЛОЖЕННОСТЬ K COVID-19

\author{
() Я.Р. Тимашева ${ }^{1,2 *}$, Ж.Р. Балхиярова ${ }^{1,2,3}$, О.В. Кочетова ${ }^{1}$
}

'Институт биохимии и генетики Уфимского федерального исследовательского центра Российской академии наук, Уфа, Россия

${ }^{2}$ Башкирский государственный медицинский университет, Уфа, Россия

зуниверситет Суррея, Гилфорд, Великобритания

Число людей с ожирением в мире достигло 700 млн человек и продолжает неуклонно увеличиваться. Проблема приобретает особую актуальность в связи с повышенным риском осложненного течения и смертности от COVID-19 у пациентов с ожирением. Увеличение распространенности ожирения, в том числе морбидного, связывают с действием внешних и поведенческих факторов, что приводит к стигматизации людей с ожирением, поскольку их проблемы считают обусловленными неправильным образом жизни, характером питания и другими управляемыми факторами. Тем не менее установлено существование наследственной предрасположенности к ожирению, которая носит выраженный полигенный характер. К развитию морбидного ожирения могут приводить редкие мутации, оказывающие значительный эффект на энергетический обмен и отложение жира, однако у большинства пациентов они не выявляются. Низкое разнообразие генов микробиома коррелирует с метаболическими нарушениями (хроническим воспалением, инсулинорезистентностью, размером адипоцитов), а также успешностью оперативных вмешательств, направленных на коррекцию веса (бариатрической хирургии), но данных об отдаленных последствиях бариатрической хирургии и изменении состава, генетического разнообразия и активности микробиома до и после хирургического вмешательства пока недостаточно. В обзоре представлены результаты исследований генетических особенностей пациентов, страдающих ожирением, молекулярных механизмов патогенеза ожирения, способствующих неблагоприятному течению коронавирусной инфекции, а также эволюции микробиома пациентов при бариатрической хирургии, проливающие свет на природу развития заболевания и создающие предпосылки для определения потенциальных мишеней для лекарственной терапии и разработки персонализированных эффективных подходов в диагностике, лечении и профилактике ожирения.

КЛЮЧЕВЫЕ СЛОВА: ожирение; морбидное ожирение; бариатрическая хирургия; кишечный микробиом; COVID-19.

\title{
CURRENT STATE OF THE OBESITY RESEARCH: GENETIC ASPECTS, THE ROLE OF MICROBIOME, AND SUSCEPTIBILITY TO COVID-19
}

\author{
(c) Yanina R. Timasheva ${ }^{1,2 *}$, Zhanna R. Balkhiyarova ${ }^{3}$, Olga V. Kochetova ${ }^{1}$
}

${ }^{1}$ Institute of Biochemistry and Genetics of Ufa Federal Research Centre of Russian Academy of Sciences, Ufa, Russia ${ }^{2}$ Bashkir State Medical University, Ufa, Russia

${ }^{3}$ University of Surrey, Guildford, United Kingdom

Obesity affects over 700 million people worldwide and its prevalence keeps growing steadily. The problem is particularly relevant due to the increased risk of COVID-19 complications and mortality in obese patients. Obesity prevalence increase is often associated with the influence of environmental and behavioural factors, leading to stigmatization of people with obesity due to beliefs that their problems are caused by poor lifestyle choices. However, hereditary predisposition to obesity has been established, likely polygenic in nature. Morbid obesity can result from rare mutations having a significant effect on energy metabolism and fat deposition, but the majority of patients does not present with monogenic forms. Microbiome low diversity significantly correlates with metabolic disorders (inflammation, insulin resistance), and the success of weight loss (bariatric) surgery. However, data on the long-term consequences of bariatric surgery and changes in the microbiome composition and genetic diversity before and after surgery are currently lacking. In this review, we summarize the results of studies of the genetic characteristics of obesity patients, molecular mechanisms of obesity, contributing to the unfavourable course of coronavirus infection, and the evolution of their microbiome during bariatric surgery, elucidating the mechanisms of disease development and creating opportunities to identify potential new treatment targets and design effective personalized approaches for the diagnosis, management, and prevention of obesity. 


\section{ВВЕДЕНИЕ}

Согласно определению Всемирной организации здравоохранения, ожирение - это патологическое накопление жира, представляющее риск для здоровья [1]. Для диагностики ожирения используется индекс массы тела (ИМТ), рассчитываемый как отношение массы тела в килограммах к квадрату роста в метрах. Нормальные показате-

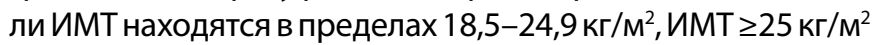
классифицируется как наличие излишней массы тела, ИМТ

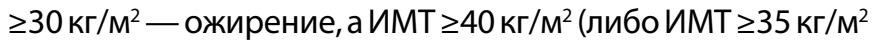
при наличии серьезных осложнений) - морбидное ожирение. В России распространенность ожирения составляет 27,5\% среди мужчин и 31,4\% среди женщин [2]. Отмечается рост числа людей, страдающих ожирением; в США доля лиц с морбидным ожирением выросла с 4,7\% в 1999-2000 гг. до 9,2\% в 2017-2018 гг., а в 1990 г. составляла лишь 0,9\% [3]. Ожирение значительно снижает ожидаемую продолжительность жизни, способствуя развитию кардиометаболических нарушений (сахарный диабет 2 типа (СД2), дислипидемии, ишемическая болезнь сердца, инсульт, артериальная гипертензия) и неметаболических заболеваний (гастроэзофагально-рефлюксная болезнь, неалкогольный стеатогепатит, цирроз печени, рак, нарушения сна, депрессия и поражение опорно-двигательного аппарата) [4].

Ожирение - это многофакторное заболевание, возникающее в результате положительного баланса энергии, когда количество энергии, обеспечиваемое потребляемой пищей, превышает затраты энергии в ходе жизнедеятельности. Избыток энергии откладывается в жировых депо в виде триглицеридов, приводя к появлению избыточной массы тела, а впоследствии - к развитию ожирения [5]. Одними из основных факторов развития ожирения принято считать изменившийся характер питания и преобладание в рационе полуфабрикатов и фастфуда, содержащих большое количество энергии, а также снижение физической активности как часть современного образа жизни [6]. Социальные факторы также вносят вклад в развитие ожирения: если в странах с низким уровнем дохода ожирением страдают, как правило, состоятельные городские жители среднего возраста, преимущественно женщины, то в странах с высоким уровнем дохода ожирение распространено среди мужчин и женщин всех возрастов, но при этом больные, как правило, относятся к социально уязвимым группам населения [7].

Несмотря на значимость влияния факторов внешней среды, нельзя недооценивать роль генетического компонента в развитии ожирения. В ходе ранних семейных [8-11] и близнецовых [12-14] исследований было установлено, что вклад генетических факторов в вариабельность ИМТ может достигать 70-80\%. Популяционные исследования распространенности ожирения в различных этнических группах также подчеркивают влияние генетических особенностей [15]. В то время как в ряде случаев ожирение является составной частью различных хромосомных синдромов и результатом влияния мутаций отдельных генов (рис. 1), по большей части, по-видимому, развитие ожирения обусловлено сложным взаимодействием внешних факторов, способствующих ожирению ("obesogenic environment") и индивидуальной наследственной предрасположенности $[16,17]$.

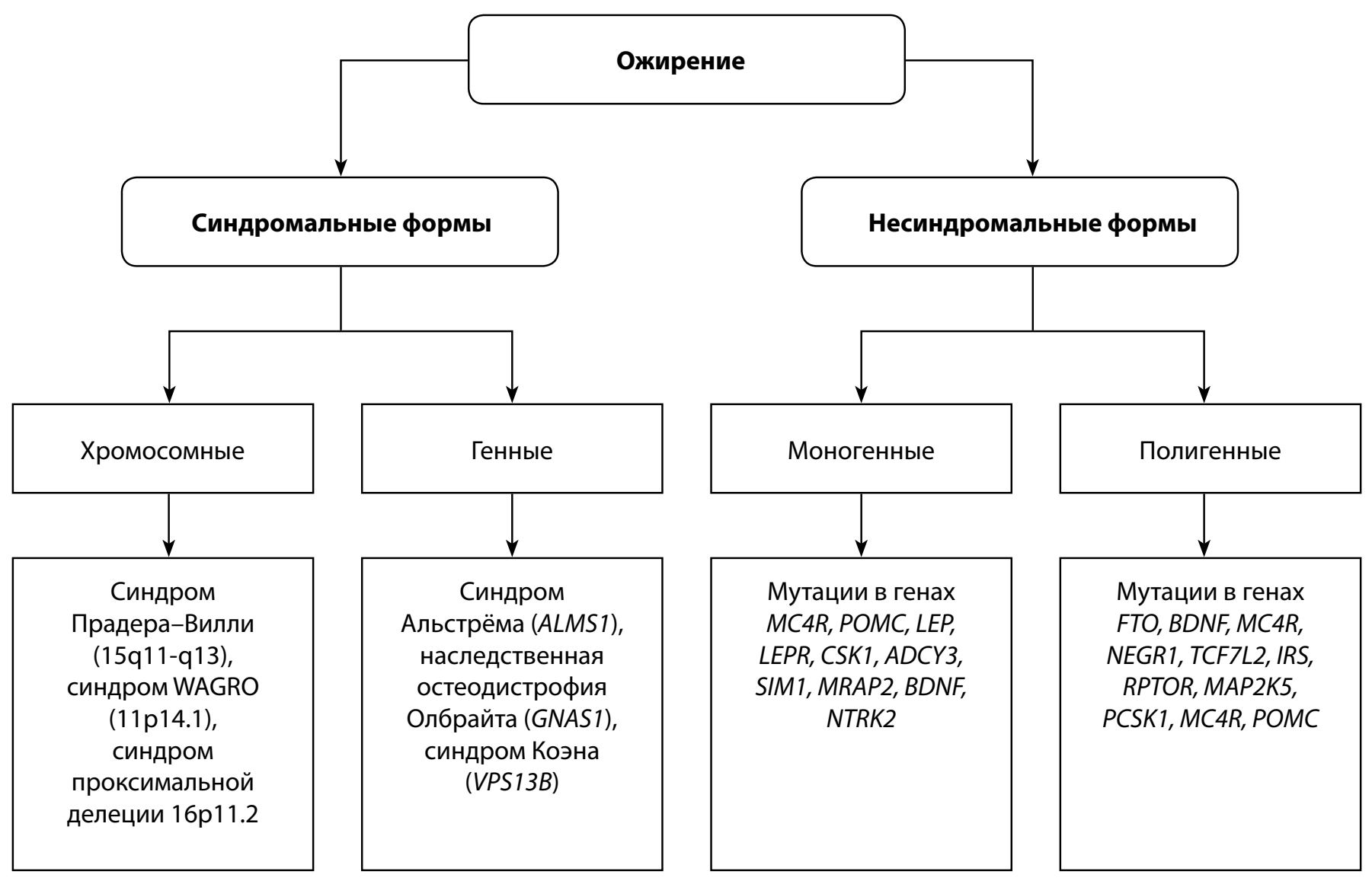

Рисунок 1. Генетическая структура ожирения. 


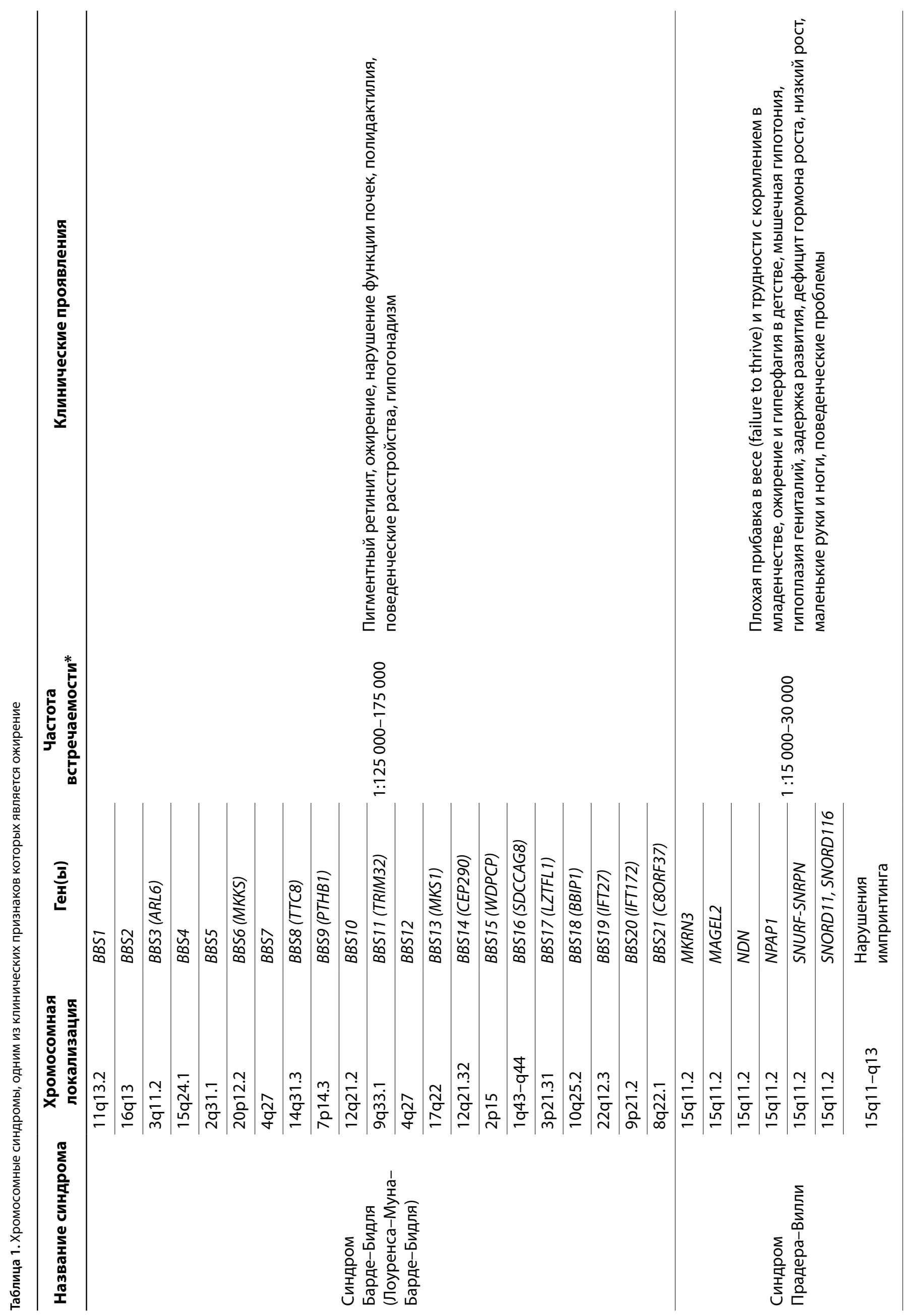




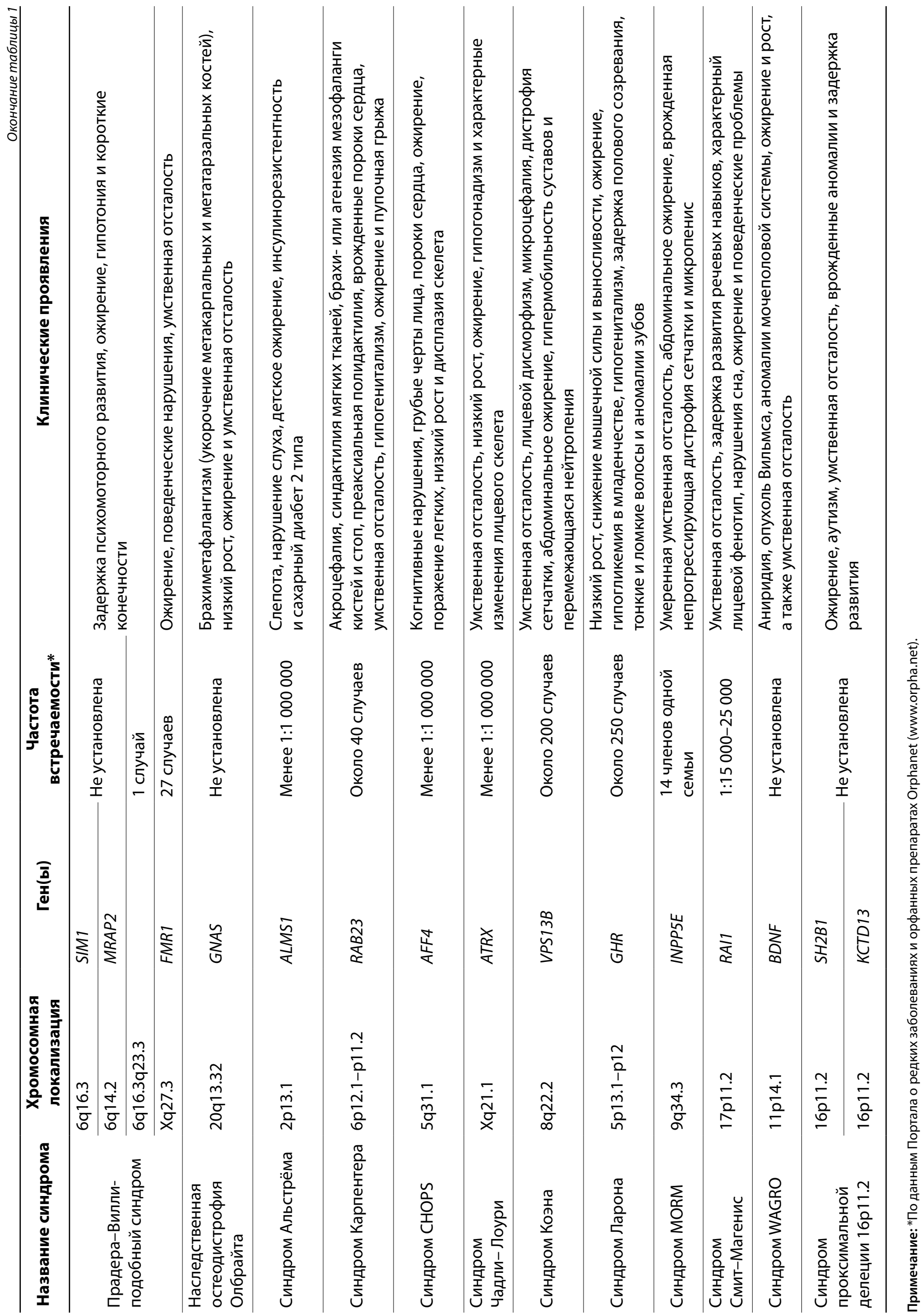




\section{СИНДРОМАЛЬНЫЕ ФОРМЫ ОЖИРЕНИЯ}

К настоящему времени В литературе описаны 79 различных синдромов, включающих ожирение в качестве одного из клинических признаков, из них 30 - с установленной генетической причиной развития (19 - полностью, 11 - частично), 27 - синдромы, развитие которых связывают с мутациями в определенном хромосомном участке, и 22 - синдромы, для которых пока не найдены ни ген(ы), ни хромосомный участок, отвечающие за их развитие [18]. Наиболее полно охарактеризованные хромосомные наследственные синдромы, связанные с развитием ожирения, представлены в таблице 1. К ним относится синдром Барде-Бидля, который, как было показано к настоящему моменту, может быть связан с дефектами 16 различных хромосом, сопровождающимися нарушениями структуры 21 гена, тогда как примерно в 25\% случаев генетическую причину заболевания установить не удается [19]. Наиболее распространенной формой ожирения, обусловленного хромосомными нарушениями, является синдром Прадера-Вилли (15q11-13). Описан Прадера-Вилли-подобный фенотип, который может наблюдаться при делециях участков хромосомы 6, включающих гены SIM1 или MRAP2, и при дупликации участка 6q16.3q23.3 с образованием сверхчисленной маркерной хромосомы (sSMC) $[20,21]$. Сообщается также о пациентах с синдромом ломкой X-хромосомы (fragile X-syndrome - FXS) с Прадера-Вилли фенотипом (Prader-Willi phenotype - PWP), у которых наблюдались возникающая в детстве гиперфагия с отсутствием чувства насыщения и ожирение, а также более выраженные, чем при FXS без PWP, поведенческие расстройства и социальная дезадаптация [22].

Кроме того, ожирение является одним из клинических проявлений таких синдромов, как псевдогипопаратиреоз la типа (наследственная остеодистрофия Олбрайта), синдром CHOPS (Cognitive impairment/Coarse

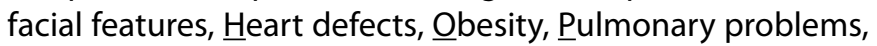
Short stature / Skeletal abnormalities), синдром MORM (Mental retardation, truncal Obesity, Retinal dystrophy and Micropenis) и синдром WAGRO (Wilms tumor, Aniridia, Genitourinary anomalies, mental Retardation, Obesity) [23].

К редким формам синдромального ожирения можно отнести синдром Ларона (дефицит рецепторов соматотропного гормона), синдром Карпентера (акроцефалополисиндактилия II типа) и синдром Коэна, частота встречаемости которого повышена в финской популяции, а также описаны семейные случаи у амишей, ирландцев, греков и некоторых других представителей средиземноморских стран.

\section{МОНОГЕННЫЕ ФОРМЫ ОЖИРЕНИЯ}

К настоящему времени развитие моногенных форм ожирения связывают с несколькими генами (MC4R, LEP, LEPR, PCSK1, ADCY3, POMC, MRAP2), продукты которых входят в состав лептин-меланокортинового пути, участвующего в регуляции энергетического обмена [24, 25]. Несмотря на то что моногенные формы ожирения встречаются чрезвычайно редко, описаны гомозиготные мутации в этих генах, обладающие полной пенетрантностью и приводящие к развитию заболевания (табл. 2). Наряду с этим выделяют так называемые олигогенные формы ожирения у взрослых и детей, которые связаны с гетерозиготными мутациями в этих же генах и характеризуются различной степенью тяжести в зависимости от влияния средовых факторов [26, 27].

Выявление мутаций в гене лептина $L E P$, связанных с развитием выраженного ожирения и сахарного диабета 2 типа у мышей, а также с морбидным ожирением у детей, положило начало обнаружению редких мутаций, приводящих к развитию ожирения [28]. Лептин регулирует энергетический баланс, действуя через меланокортин-зависимый и меланокортин-независимый пути [29]. Благодаря связыванию лептина со своими рецепторами в гипоталамусе, центральная нервная система получает сигналы от жировой ткани о том, что в организме достаточно запасов энергии. В гипоталамусе находится центр, осуществляющий долгосрочную регуляцию энергетического обмена путем интеграции сигналов периферического и центрального происхождения об энергетическом и нутрициональном статусе организма и состоянии внешней среды. Мутации в гене лептина приводят к гиперфагии (перееданию), сниженной двигательной активности, снижению тонуса симпатической нервной системы, гипофункции щитовидной железы, гипогонадизму и нарушению Т-клеточного иммунитета. Есть сообщения о том, что терапия рекомбинантным лептином благоприятно сказывалась на состоянии пациентов с морбидным ожирением, сахарным диабетом и гипогонадизмом, обусловленными дефицитом лептина [30].

На молекулярном уровне действие лептина проявляется стимуляцией выработки проопиомеланокортина (РОМС) в нейронах аркуатного и дорсомедиального ядер гипоталамуса. РОМС является предшественником ряда пептидных гормонов, в том числе альфа-меланоцитстимулирующего гормона (а-MSH), или альфа-меланотропина, который, связываясь с рецептором меланокортина 4 (MC4R), подавляет аппетит. Было обнаружено, что мутации в генах POMC и MC4R связаны с развитием морбидного ожирения [31, 32]. Следует отметить, что гетерозиготные мутации в гене $M C 4 R$ выявляются у $5 \%$ пациентов с ожирением, развивающимся в детском возрасте; таким образом, дефекты гена MC4R являются наиболее частой причиной моногенного ожирения [33]. При мутациях гена POMC, связанных с дефицитом пептида, могут также возникать нарушения пигментного обмена вследствие недостаточности альфа-меланотропина, что обусловливает характерную рыжую окраску волос пациентов [32].

Дифференциальное расщепление РОМС, которое может приводить к образованию а-MSH, а также адренокортикотропного гормона и бета-эндорфина, осуществляется с помощью пропротеинконвертазы-1 (PCSK1), которая также участвует в процессинге проинсулина и проглюкагона в поджелудочной железе [34]. У гомозигот и компаунд-гетерозигот по ряду мутаций в гене PCSK1 может нарушаться процессинг РОМС, что проявляется в развитии ожирения, глюкокортикоидной недостаточности, гипогонадотропного гипогонадизма, постпрандиальной гипогликемии и мальабсорбции $[35,36]$.

Ген $A D C Y 3$ кодирует аденилатциклазу, расположенную в первичных ресничках, в частности в гипоталамусе. Мутации в гене приводят к развитию ожирения 
Таблица 2. Моногенные формы ожирения

\begin{tabular}{|c|c|c|c|}
\hline Ген & $\begin{array}{l}\text { Хромосомная } \\
\text { локализация }\end{array}$ & Продукт & Клинические проявления \\
\hline$M C 4 R$ & $18 q 21.32$ & $\begin{array}{l}\text { Рецептор } \\
\text { меланокортина } 4\end{array}$ & $\begin{array}{l}\text { Морбидное ожирение с ранним началом, гиперфагия, } \\
\text { гиперинсулинемия, увеличение безжировой массы тела, } \\
\text { повышение минеральной плотности костей }\end{array}$ \\
\hline POMC & $2 p 23.3$ & Проопиомеланокортин & $\begin{array}{l}\text { Ожирение тяжелой степени с манифестацией } \\
\text { в раннем возрасте, гиперфагия, недостаточность } \\
\text { адренокортикотропного гормона, гипотиреоз, рыжий цвет } \\
\text { волос }\end{array}$ \\
\hline LEP & 7q32.1 & Лептин & $\begin{array}{l}\text { Морбидное ожирение с ранним началом, дефицит } \\
\text { гонадотропного и тиреотропного гормонов, иммунные } \\
\text { нарушения }\end{array}$ \\
\hline LEPR & $1 p 31.3$ & Рецептор лептина & $\begin{array}{l}\text { Морбидное ожирение с ранним началом, дефицит } \\
\text { гонадотропного, соматотропного и тиреотропного } \\
\text { гормонов, иммунные нарушения }\end{array}$ \\
\hline$A D C Y 3$ & $2 \mathrm{p} 23.3$ & Аденилатциклаза 3 & $\begin{array}{l}\text { Ожирение (абдоминальное), инсулинорезистентность, } \\
\text { дислипидемия, диабет } 2 \text { типа, нарушения обоняния }\end{array}$ \\
\hline$B D N F$ & $11 p 14.1$ & $\begin{array}{l}\text { Нейротрофический } \\
\text { фактор мозга }\end{array}$ & $\begin{array}{l}\text { Морбидное ожирение, гиперфагия, гиперактивность, } \\
\text { когнитивные расстройства, нарушения памяти и болевой } \\
\text { чувствительности }\end{array}$ \\
\hline NTRK2 & $9 q 21.33$ & $\begin{array}{l}\text { Нейротрофический } \\
\text { рецептор } \\
\text { тирозинкиназы } 2\end{array}$ & $\begin{array}{l}\text { Морбидное ожирение с ранним началом, задержка } \\
\text { развития, стереотипное поведение, нарушения памяти } \\
\text { и обучения, сниженная болевая чувствительность }\end{array}$ \\
\hline MRAP2 & $6 q 14.2$ & $\begin{array}{l}\text { Вспомогательный } \\
\text { белок } 2 \text { рецептора } \\
\text { меланокортина } 2\end{array}$ & $\begin{array}{l}\text { Ожирение различной степени, гиперфагия, } \\
\text { метаболический синдром (артериальная гипертензия, } \\
\text { гипергликемия) }\end{array}$ \\
\hline PCSK1 & $5 q 15$ & $\begin{array}{l}\text { Пропротеин- } \\
\text { конвертаза } \\
\text { субтилизина/кексина } \\
\text { типа } 1\end{array}$ & $\begin{array}{l}\text { Морбидное ожирение с ранним началом, недостаточность } \\
\text { гонадотропного, соматотропного, тиреотропного } \\
\text { гормонов, постпрандиальный гипогликемический } \\
\text { синдром, центральный несахарный диабет, хроническая } \\
\text { тяжелая диарея с мальабсорбцией, возникающая } \\
\text { в неонатальном периоде }\end{array}$ \\
\hline SIM1 & $6 q 16.3$ & $\begin{array}{l}\text { Целенаправленный } \\
\text { гомолог-1 }\end{array}$ & $\begin{array}{l}\text { Морбидное ожирение с ранним началом, задержка } \\
\text { развития, гипотония, эмоциональная лабильность, } \\
\text { аутистическое поведение }\end{array}$ \\
\hline
\end{tabular}

вследствие нарушения передачи сигнала циклического AMФ (цАМФ) в пути, инициированном MC4R. Характерной особенностью моногенных форм ожирения, обусловленных дефектом $A D C Y 3$, являются сопутствующие им нарушения обоняния (аносмия) [37, 38].

Ген SIM1 кодирует фактор транскрипции, участвующий в сигналинге MC4R и предположительно задействованный В формировании супраоптического и паравентрикулярного ядер гипоталамуса [20, 39, 40]. Гетерозиготные мутации гена связаны с развитием морбидных форм ожирения, иногда сопровождающихся снижением интеллектуального уровня [20, 39].
Ген MRAP2 кодирует вспомогательный трансмембранный протеин, который связывается с рецепторами, сопряженными с G-белком, и тем самым регулирует передачу обеспечиваемого ими сигнала, в частности, стимулирует выработку цАМФ, индуцированную MC4R, в ответ на aMSH $[41,42]$. К настоящему времени идентифицировано более 20 мутаций в гене MRAP2, связанных с развитием ожирения [43]. В отличие от других моногенных форм, ожирение, вызванное дефицитом MRAP2, как правило, не является морбидным, но сопровождается развитием гипергликемии и/или артериальной гипертензии [43]. Это связывают с тем, что, в отличие от других 
генов лептин-меланокортинового пути, MRAP2 экспрессируется в других органах и тканях, помимо головного мозга, в частности бета-клетках островков Лангерганса поджелудочной железы, и может влиять на их функцию, снижая секрецию инсулина [44].

Описаны также случаи моногенного ожирения, обусловленные мутациями в гене нейротрофического рецептора тирозинкиназы 2 (NTRK2) и его лиганда нейротрофического фактора мозга (BDNF), характерной особенностью которых являются когнитивные расстройства, нарушения памяти, обучения и болевой чувствительности, предположительно, вследствие измененной функции гипоталамуса $[45,46]$.

\section{ПОЛИГЕННЫЕ ФОРМЫ ОЖИРЕНИЯ}

Несмотря на то что к настоящему моменту выявлено значительное количество моногенных форм, у большинства пациентов ожирение представляет собой многофакторное заболевание, обусловленное сочетанным влиянием факторов внешней среды и генетических факторов. С помощью полногеномных ассоциативных исследований (GWAS) было идентифицировано более 200 полиморфных вариантов, ассоциированных с ожирением (https://www.ebi.ac.uk/gwas/efotraits/EFO_0001073), и более 4200, ассоциированных с ИМТ (https://www.ebi.ac.uk/ gwas/efotraits/EFO_0004340). Тем не менее вместе эти локусы объясняют лишь 5\% индивидуальной вариабельности ИМТ [47]. Наследственная предрасположенность к ожирению может также проявляться опосредованно, в виде измененных поведенческих реакций на средовые факторы, или ген-средовых взаимодействий [48]. В частности, особенности питания, физическая активность, социоэкономический статус могут модифицировать степень проявления генетической предрасположенности к ожирению [49]. Несмотря на то что урбанизированный образ жизни современного человека, несомненно, повлиял на развитие эпидемии ожирения, нельзя упускать из виду то обстоятельство, что эволюционно сложившиеся молекулярные механизмы обмена направлены на накопление и депонирование запасов энергии и, следовательно, также способствуют развитию ожирения. Предполагается, что такие негенетические факторы, как характер питания, физические упражнения или хирургические вмешательства, направленные на снижение веса, индуцируют динамические изменения эпигенетических паттернов, модулируя тем самым активность генов [16]. Были обнаружены значимые корреляции клинических параметров, характерных для ожирения, и эпигенетических паттернов, обнаруживаемых в клетках крови, жировой ткани, печени и скелетной мускулатуры [50-53].

Анализ результатов GWAS показал, что локусы, ассоциированные с ожирением, включают гены, продукты которых участвуют в контроле аппетита и чувства насыщения (MC4R, ген нейротрофического фактора головного мозга - $B D N F$, ген регулятора роста нейронов 1 - NEGR1), выработки инсулина (ген фактора транскрипции 7, подобного второму, - TCF7L2, ген субстрата 1 инсулинового рецептора — IRS1), образования клеток жировой ткани, а также энергетического и липидного метаболизма (ген, ассоциированный с жировой массой и ожирением, - FTO; ген регуляторного белка, связанного с mTOR, - RPTOR; ген митоген-активируемой киназы 5 - MAP2K5). Кроме того, анализ генов, ассоциированных с кардиометаболическими заболеваниями, имеющими общий патогенез (ожирение, диабет, артериальная гипертензия, ишемическая болезнь сердца, рак молочной железы, синдром поликистозных яичников, рак почки), позволил выявить локусы и молекулярные пути, являющиеся общими для этих заболеваний [54]. Также следует отметить, что вдобавок к редким мутациям потери функции (loss-of-function) в генах PCSK1, MC4R и POMC также обнаруживаются полиморфные варианты, ассоциированные с полигенными формами ожирения в различных популяциях [55-58].

Безусловно, GWAS являются мощным инструментом для анализа генетической архитектуры сложных признаков, таких как ожирение, но интерпретация результатов GWAS затруднена. Большинство генетических вариантов, ассоциированных с ожирением, локализовано в некодирующих участках генома, в которых могут находиться регуляторные элементы, играющие важную роль в контроле транскрипционной активности генов, причем зачастую расположенные вдали от генетического варианта, для которого обнаружена ассоциация с ожирением. Поэтому, основываясь только на информации о расположении того или иного полиморфного варианта вблизи какого-либо гена, невозможно сделать вывод о том, что различные аллели этого полиморфизма способны изменять функцию этого гена. В частности, долгое время оставался неясным молекулярный механизм, лежащий в основе выявленных ассоциаций полиморфных вариантов в гене FTO с ожирением, пока не было установлено, что полиморфный вариант rs1421085, находящийся в интроне гена FTO и ассоциированный с ИМТ, связан с нарушением последовательности репрессора гена белка 4A, содержащего АТ-богатый интерактивный домен (ARID5B), который регулирует экспрессию генов из семейства ирокез-гомеобокс IRX3 и IRX5 [59, 60]. Это приводит к нарушению термогенеза, увеличению размеров жировых клеток и к ожирению.

\section{РОЛЬ НАСЛЕДСТВЕННЫХ ФАКТОРОВ В РАЗВИТИИ НАРУШЕНИЙ ПИЩЕВОГО ПОВЕДЕНИЯ}

Хорошо известно, что такие психические нарушения, как расстройства приема пищи (нервная анорексия, нервная булимия и компульсивное переедание), могут приводить к развитию алиментарного ожирения. Использование близнецовых и семейных методов позволило получить подтверждение роли наследственности в развитии ожирения и нарушений пищевого поведения [61-63]. В частности, было продемонстрировано, что от $47 \%$ до $90 \%$ индивидуальной вариабельности массы тела можно отнести за счет влияния генетических факторов [64]. Коэффициент наследуемости одного из расстройств пищевого поведения - нервной булимии - составил 55\%, а у родственников лиц, страдающих нервной анорексией, шансы развития расстройств приема пищи были повышены в 11,3 раза по сравнению с родственниками лиц из группы контроля $[62,65]$.

В качестве попытки объяснить взаимосвязь наследственности и массы тела была предложена теория поведенческой восприимчивости (behavioural susceptibility 
theory, BST), согласно которой генетические факторы оказывают влияние на вес путем регуляции аппетита, что проявляется в виде различных паттернов пищевого поведения [66]. Согласно этой теории, ожирение является результатом сочетания генетической наклонности к перееданию и средовых факторов, создающих благоприятные условия для повышенного потребления пищи, что приводит к положительному энергетическому балансу. Показано, что определенные паттерны пищевого поведения ассоциированы с индивидуальными различиями в наборе веса и массе тела и что различия пищевого поведения являются наследуемыми $[67,68]$.

Обнаружены ассоциации с перееданием полиморфных вариантов в генах, продукты которых участвуют в регуляции чувства насыщения (грелин, рецептор меланокортина 4, дофаминовый рецептор D2, белок-переносчик серотонина и др.), а также связь с развитием булимии полиморфных вариантов в генах рецептора эстрогена 1, каннабиноидного рецептора 1, а также в гене FTO [69]. Результаты близнецового исследования с использованием полигенных шкал риска (polygenic risk scores - PRS) продемонстрировали, что ассоциация с ожирением PRS для ИМТ была опосредована различными паттернами пищевого поведения (нерегулярным и нездоровым питанием у мужчин и привычкой к перекусам у представителей обоих полов) [70].

Ранее было обнаружено, что экспрессия генов, связанных с ИМТ, повышена в центральной нервной системе (ЦНС), в областях, отвечающих за процессы обучения и консолидации памяти, в частности, гиппокампе [71]. Впоследствии было показано, что для областей мозга, обогащенных генами, ассоциированными с ИМТ, характерны общие транскрипционные сигнатуры, связанные с ожирением [72]. Для пациентов с генетическими дефектами выработки лептина, у которых при рождении наблюдается нормальный вес, затем рано возникает гиперфагия и развиваются морбидное ожирение, сниженный иммунитет и ряд нейроэндокринных расстройств, включающих аменорею и инсулинорезистентность, был характерен тип пищевого поведения, связанный с почти непрерывной потребностью в еде, причем энергетическая ценность потребляемой пищи была почти в пять раз выше, чем у лиц без ожирения [73]. Назначение таким пациентам препарата, являющегося аналогом лептина, было связано с уменьшением чувства голода, увеличением оценки насыщения, снижением энергетической ценности потребляемой пищи, повышением уверенности в себе, и приводило к значительному снижению массы тела после 15 нед применения [74, 75].

Следует отметить, что недостаточность лептина связана с развитием депрессии как у человека, так и у модельных объектов [76]. Роль лептина в формировании пищевого поведения включает в себя не только гомеостатический компонент контроля энергетического баланса, но и гедонистический аспект приема пищи [74]. Сообщалось о том, что лептин воздействует на области головного мозга, образующие систему вознаграждения, снижая степень положительной обратной связи за счет подавления дофаминергической передачи нервных импульсов [77]. Другим аспектом влияния лептина на пищевое поведение является его участие в регуляции восприятия сладкого вкуса вкусовыми рецепторами [78].
Результаты нескольких исследований указывают на возможную роль в развитии нарушений пищевого поведения гормонов, секретируемых белой жировой тканью (адипокинов), в частности адипонектина [79-81]. Установлено, что адипонектин действует в аркуатном ядре гипоталамуса, усиливая аппетит путем активации рецептора AdipoR1 и аденозинмонофосфат-активируемой протеинкиназы (AMPK) [82]. Снижение концентрации адипонектина в плазме обнаруживалось у пациентов с инсулинорезистентностью, ожирением, диабетом 2 типа и ишемической болезнью сердца [83, 84].

\section{РОЛЬ КИШЕЧНОГО МИКРОБИОМА В РАЗВИТИИ ОЖИРЕНИЯ}

Одним из важных факторов, влияющих на развитие ожирение, является состав микробного сообщества, населяющего желудочно-кишечный тракт человека, исследования которого были начаты еще в прошлом веке [85]. Последние десятилетия ознаменовались быстрым увеличением числа исследований симбионтной роли микроорганизмов в организме человека. Зачастую это приводит к противоречиям в использовании специальных терминов. Как правило, для обозначения таксономического состава микроорганизмов в определяемом образце используют термин «микробиота», для характеристики набора генов, содержащихся в образце, применяют термин «метагеном», а «микробиомом» называют совокупность генов микробного сообщества [86]. Общее количество бактерий, населяющих желудочно-кишечный тракт человека, достигает $10^{14}$, превышая общее число клеток организма [87], в то время как количество генов, составляющих кишечный микробиом, превосходит количество генов в геноме человека почти в 1000 раз [88]. В микробном сообществе кишечника человека преобладают пять типов бактерий: Actinobacteria, Bacteroidetes, Firmicutes, Proteobacteria и Verrucomicrobia [89]. К настоящему времени накоплен достаточно большой объем данных о механизмах влияния микробиоты кишечника на развитие ожирения (рис. 2) [86, 90-92].

Более 15 лет назад было отмечено, что у мышей, которые находились в стандартных лабораторных условиях, количество жировой ткани было намного выше, чем у мышей, содержавшихся в безмикробной среде [93]. Впоследствии были обнаружены значительные различия в бактериальном составе кишечника у мышей с генетической моделью ожирения (ob/ob) по сравнению с мышами без ожирения (ob/+) и мышами дикого типа (+/+), находившимися на одинаковой диете, богатой углеводами; в частности, у мышей с ожирением было относительно снижено число бактерий типа Bacteroidetes и повышено содержание бактерий типа Firmicutes [94]. Перенос микробиома мышей с ожирением стерильным особям приводил к значительному увеличению содержания жира у колонизированных мышей [95].

Для изучения влияния генетических факторов на состав микробиоты человека в основном используется метод анализа ассоциаций. В результате GWAS были выявлены локусы генов, ассоциированные с определенными паттернами кишечной микробиоты [96-98]. Полиморфный локус в гене FUT2 ассоциирован с численностью бактерий Ruminococcus torques семейства Lachnospiraceae 


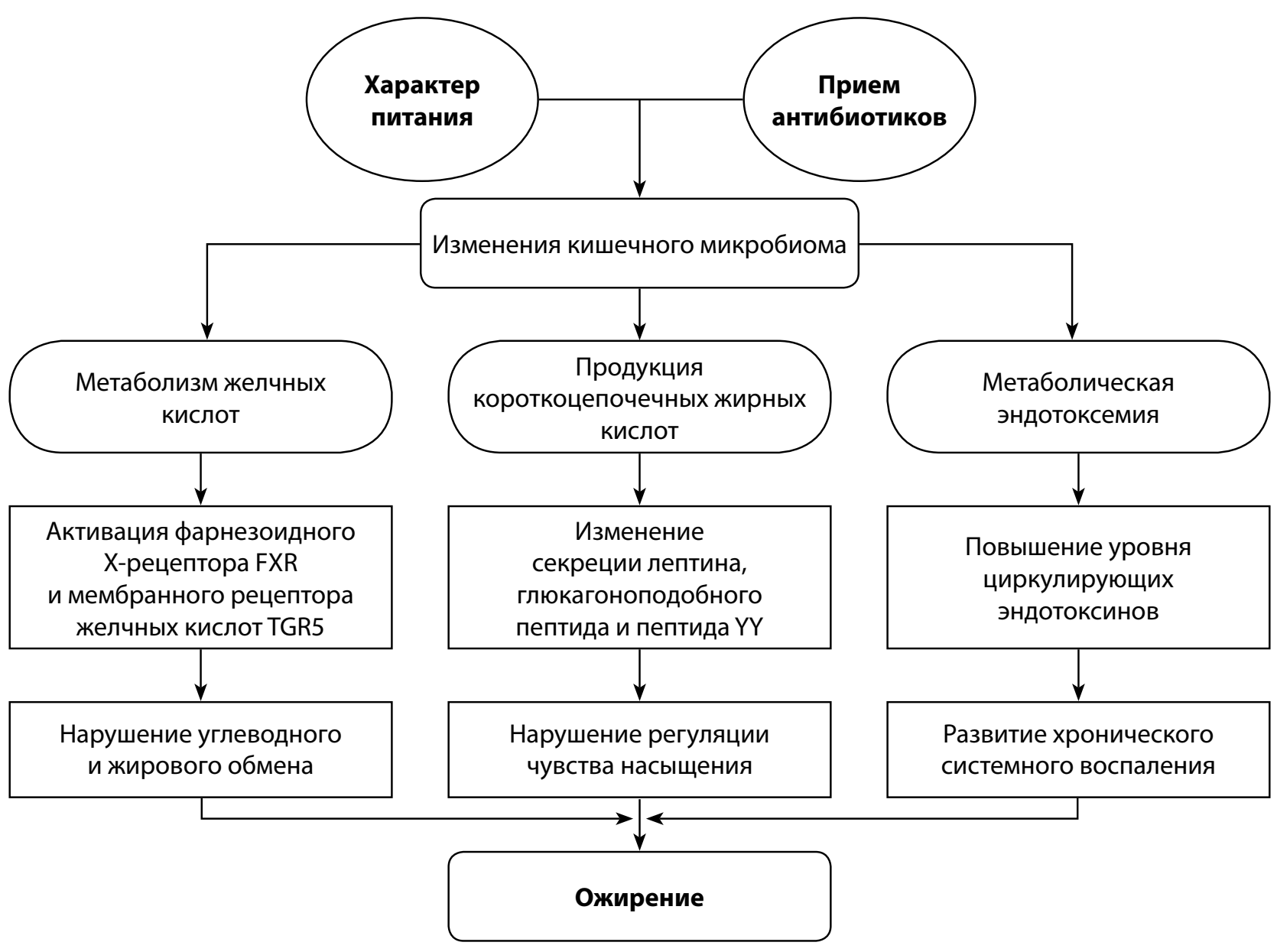

Рисунок 2. Метаболические последствия изменения микробиома кишечника.

класса Clostridia типа Firmicutes, которые специализируются на расщеплении сложных углеводов [99]. Ген FUT2 кодирует фермент альфа-1,2-фукозилтрансферазу, отвечающую за секрецию фукозилированных гликанов слизистой оболочкой желудочно-кишечного тракта. Продемонстрировано, что у лиц, гомозиготных по полиморфному варианту, связанному с появлением стоп-кодона в гене FUT2 (rs601338*A/A), не экспрессируются антигены системы АВ0 в клетках слизистой оболочки кишечника, а также уменьшена численность бактерий Ruminococcus torques и Ruminococcus gnavus [100]. В локусе 9q21 обнаружены SNP, ассоциированные с увеличением численности бактерий рода Allisonella семейства Veillonellaceaе класса Clostridia типа Firmicutes [100]. Локус 9q21 включает ген RFK, кодирующий фермент рибофлавинкиназу, который катализирует фосфорилирование витамина В2 (рибофлавина), и GCNT1, кодирующий фермент гликозилтрансферазу, участвующую в биосинтезе муцина. Эти ферменты вовлечены в метаболизм бактерий кишечного микробиома и регуляцию иммунной защиты, играя важную роль во взаимодействии организма хозяина и микробиоты кишечника [101]. Полиморфный маркер rs61841503, ассоциированный с численностью бактерий рода Peptostreptococcaceae класса Clostridia типа Firmicutes, расположен в гене CUBN (10p13), кодирующем белок кубилин, который является кишечным рецептором для витамина $\mathrm{B}_{12}$ и требуется для его абсорбции [100]. Витамин $\mathrm{B}_{12}$ необходим для адекватного взаимодействия организма хозяина с микробиомом; в эксперименте in vitro были продемонстрированы существенные изменения микробного состава кишечника после добавления витамина $\mathrm{B}_{12}$ [102]. В локусе $2 q 36$ идентифицирован блок сцепления, включающий 10 полиморфных вариантов, ассоциированных с семейством Peptococcaceae класcа Clostridia типа Firmicutes, для которого обнаружена отрицательная связь с уровнями хромогранина А и кальпротектина, являющихся маркерами воспаления в кишечнике [100]. Данный блок локализован в межгенном пространстве рядом с геном субстрата инсулинового рецептора IRS1, связанным с развитием инсулинорезистентности и диабета 2 типа [103]. Продемонстрировано, что так называемая «западная диета», отличающаяся высоким содержанием жиров и углеводов, воздействует на состав микробиома кишечника, способствуя повышенному образованию желчных кислот, в частности, дезоксихолевой кислоты, вызывая активацию сигналинга фарнезоидного Х-рецептора и интерферона I, что приводит к повреждениям клеток Панета, обеспечивающих иммунную защиту тонкого кишечника [104]. Наиболее значимая ассоциация с составом микробиоты была обнаружена для локуса гена лактазы LCT, связанного с повышением содержания Bifidobacterium, отражающим взаимосвязь генетических факторов и характера питания [100].

Повышение числа бактерий типа Firmicutes и снижение содержания бактерий типа Bacteroidetes является характерным признаком микробиоты больных с ожирением. Обратное соотношение наблюдалось после 1 года соблюдения диеты или бариатрической хирургии (шунтирования желудка) $[90,105]$. У пациентов с ожирением 
также наблюдается сниженное содержание бактерий типа Bacteroidetes по сравнению с лицами с нормальным ИМТ или пациентами с анорексией, но количество бактерий типа Firmicutes при этом не отличается. Метагеномные исследования близнецовых пар с ожирением и без такового продемонстрировали, что при ожирении снижалось бактериальное разнообразие и содержание Bacteroidetes, но повышалась доля Actinobacteria [92].

Несмотря на активное проведение исследований влияния микробиоты на развитие морбидного ожирения, в настоящее время мало данных о влиянии бариатрической хирургии на микробиом пациентов с ожирением. Оценка состояния микробиоты после бариатрической хирургии (бандажирования или шунтирования желудка по Roux-Y) позволила обнаружить снижение генетического разнообразия, коррелирующее с висцеральным ожирением и наличием осложнений (диабета, артериальной гипертензии), у 75\% пациентов [106]. Результаты анализа микробиоты беременных женщин с бариатрическими хирургическими вмешательствами в анамнезе продемонстрировали, что у перенесших мальабсорбтивные операции наблюдалось увеличение числа бактерий Enterococcus и Streptococcus (тип Firmicutes), Escherichia/Shigella (тип Proteobacteria) и Rothia (тип Actinobacteria) и снижение содержания Anaerostipes (тип Firmicutes) [107]. Сообщается также о повышении количества Firmicutes и Proteobacteria у пациентов после шунтирования желудка, в то время как после рукавной гастропластики наблюдалось увеличение числа Bacteroidetes [108]. Отмечается также повышение содержания Lachnospiraceae и Roseburia (тип Firmicutes) у пациентов, достигнувших ремиссии диабета после хирургического вмешательства [108]. Спустя 10 лет после хирургического лечения морбидного ожирения у пациентов было повышено содержание Verrucomicrobiaceae (тип Verrucomicrobia) и Streptococcaceae (тип Firmicutes) и снижено содержание Bacteroidaceae (тип Bacteroidetes) по сравнению с неоперированными пациентами [109]. Относительное повышение содержания Akkermansia muciniphila (тип Verrucomicrobia) коррелировало с ремиссией диабета [109]. У пациентов после шунтирования желудка по Roux-Y было продемонстрировано увеличение содержания протеобактерий Rothia, Aggregatibacter, Granulicatella, Citrobacter, Janthinobacterium и Klebsiella, а также наблюдалось изменение содержания бактерий из рода Firmicutes (повышение числа Streptococcus, Enterococcus, Lactococcus, Veillonella и Granulicatella и снижение Ruminococcus, Blautia и Roseburia) [110]. Изучение микробиоты пациентов с ожирением, в том числе морбидным, и исследование эволюции микробиома после операций бариатрической хирургии представляет значительный интерес для создания методов таргетной терапии.

\section{ОЖИРЕНИЕ И COVID-19}

В настоящее время человечество столкнулось с глобальной угрозой в виде пандемии COVID-19, вызванной новым коронавирусом тяжелого острого респираторного синдрома 2 (severe acute respiratory syndrome coronavirus 2 - SARS-CoV-2). COVID-19 характеризуется высоким уровнем заболеваемости и смертности среди лиц, имеющих сопутствующую патологию, в особенности поражение сердечно-сосудистой системы и ожирение. Подтверждена ассоциация между ожирением

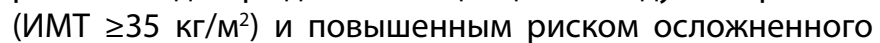
течения и смертности от COVID-19 [111-117]. Результаты анализа генетических факторов риска развития ожирения и COVID-19 с использованием данных GWAS, выполненного в когорте Биобанка Великобритании (UK Biobank), продемонстрировали, что PRS для ИМТ были значимо ассоциированы с риском тяжелого течения коронавирусной инфекции [118]. При проведении GWAS была обнаружена связь с COVID-19, в том числе с осложненным течением, локуса гена $A B 0$, находящегося в блоке сцепления с полиморфными вариантами, ассоциированными с уровнем глюкозы и инсулина в крови, уровнем гликированного гемоглобина, инсулинорезистентностью, диабетом, уровнем липопротеидов низкой плотности и триглицеридов $[119,120]$. Другой полиморфный вариант, ассоциированный с течением COVID-19, расположен в локусе 5p13.3 в гене рецептора системы натрийуретических пептидов типа C (NPR3) и находится в состоянии неравновесного сцепления с маркерами ожирения, в том числе абдоминального [121, 122]. Ранее было продемонстрировано, что ген NPR3 в адипоцитах является мишенью микроРHK miR-146а, которая участвует в регуляции инсулинорезистентности и липогенеза [123]. Использование метода менделевской рандомизации, позволяющего определять причинно-следственные связи, выявило ассоциацию между генетически детерминированным повышением ИМТ и уровня липопротеидов низкой плотности с риском COVID-19 [124]. Таким образом, результаты ассоциативных исследований дают основания полагать, что в основе наблюдаемой корреляции ожирения с риском COVID-19 и неблагоприятными исходами заболевания лежат полиморфные варианты в генах, влияющих на углеводный и липидный обмен.

Известно, что вирус SARS-CoV-2 использует для проникновения в клетки рецептор ACE2, который экспрессирован в подкожной и висцеральной жировой ткани на значительно более высоком уровне, чем в ткани легких $[125,126]$. Отмечается, что по уровню экспрессии ACE2 в жировых клетках и их предшественниках пациенты с ожирением схожи с индивидуумами с нормальной массой тела, но поскольку у пациентов с ожирением повышено содержание жировой ткани в организме и, соответственно, количество АCE2-продуцирующих клеток, полагают, что это приводит к повышенной выработке ACE2 [126-128].

Одним из предполагаемых рецепторов SARS-CoV-2 является дипептидилпептидаза-4 (DPP4), которая была идентифицирована как один из новых адипокинов жировой ткани [129]. DPP4 представлена на апикальных поверхностях поляризованного эпителия различных органов, таких как легкие и печень, и играет важную роль в гомеостазе глюкозы, воспалении и иммунной системе [130, 131]. Продемонстрировано, что повышение уровня DPP4 приводит к хронической субклинической активации иммунной системы и персистирующему воспалению [130]. Активация DPP4 отмечена при ожирении, особенно при развитии инсулинорезистентности, а ингибирование DPP4 предотвращало развитие фиброза белой жировой ткани у мышей с ожирением $[132,133]$. Клетки жировой 
ткани, предположительно, являются одним из основных источников циркулирующей DPP4; в частности, были продемонстрированы секреция DPP4 клетками жировой ткани и повышение уровня циркулирующей DPP4 у пациентов с ожирением по сравнению с индивидуумами с нормальной массой тела $[129,134]$. Повышенная экспрессия DPP4 в жировой ткани пациентов с ожирением может способствовать проникновению SARS-CoV-2 В клетки. Интересно, что ингибиторы DPP4 (глиптины) предложены в качестве препаратов 2-4-го ряда для лечения диабета 2-го типа и могут использоваться в комбинированной терапии COVID-19 [135].

CD147, предполагаемый альтернативный рецептор для SARS-CoV-2, положительно коррелирует с ИМТ, возможно, влияя на заболеваемость и осложненное течение COVID-19 у пациентов с ожирением [128]. Протеаза TMPRSS2, необходимая для праймирования шиповидного белка (S-белка) вируса SARS-CoV-2, экспрессируется в жировой ткани, хотя и на низком уровне, в то время как протеаза фурин, обеспечивающая активацию вируса путем расщепления S-белка, экспрессируется в жировой ткани при ожирении, а также во время адипогенеза [136, 137]. Фурин обеспечивает проникновение SARS-CoV-2 в клетки, а за счет праймирования S-белка способствует выходу из клеток вирусных частиц, которые могут атаковать соседние клетки или попадать в кровоток [138].

Избыточное содержание жира приводит к превышению возможностей клеток жировой ткани по его хранению, вследствие чего при биопсии жировой ткани тучных людей с инсулинорезистентностью обнаруживается увеличение количества погибших и отмирающих адипоцитов, сопровождающееся скоплением инфильтрирующих макрофагов [139]. Активированные макрофаги способствуют развитию системного воспаления, характеризующегося увеличением циркулирующих уровней цитокинов, таких как фактор некроза опухоли альфа (TNF), интерлейкины-6 (IL6) и 1-бета (IL1b) [140]. Системное хроническое воспаление является патогенетической точкой соприкосновения, предрасполагающей к развитию тяжелых осложнений у пациентов с ожирением при COVID-19 [141]. Быстрое ухудшение состояния у пациентов с COVID-19 связано с провоспалительным цитокиновым штормом, характеризующимся увеличением системного уровня TNF, IL6, IL2 и IL7, гранулоцитарного колониестимулирующего фактора, хемокинов CXCL10 и CCL2 [142].

Продемонстрировано, что морбидное ожирение приводит к нарушению почти всех функций и свойств стромальных/стволовых клеток жировой ткани (ASC) и способствует переключению нормальной регуляторной активности на прогипоксическую и провоспалительную [143, 144]. При ожирении ASC и мезенхимальные стволовые клетки (MSC) теряют свои основные свойства, что сопровождается нарушением их мультипотентного состояния из-за снижения экспрессии генов основных факторов плюрипотентности - октамерсвязывающего белка 4 (OCT4), фактора транскрипции SRY-Box 2 (SOX2), фактора транскрипции гомеобокса Nanog (NANOG), гомолога экзонуклеазы-1 РНК (REX1) и гомеобоксного белка hox-C10 (HOXC10) [145, 146]. У пациентов с ожирением наблюдается снижение дифференцировки эндотелиальных клеток, о чем свидетельствует снижение секреции фактора роста эндотелия сосудов A (VEGF), фактора роста гепатоцитов (HGF), фактора роста фибробластов 2 (FGF2) и тромбоцитарного фактора роста (PDGF) $[147,148] ;$ изменение иммуномодулирующей способности, что проявляется ингибированием пролиферации лимфоцитов, рекрутированием воспалительных моноцитов и поляризацией макрофагов М1 [149]; изменение внутриклеточного метаболизма, проявляющееся в увеличении продукции активных форм кислорода, нарушении функции митохондрий и подавлении сиртуина 1-6 (SIRT1-6) [143, 150, 151].

Как уже отмечалось, при ожирении могут возникать повреждения первичных ресничек, в том числе в ASC, что нарушает их уникальную сигнальную функцию. Цитокины IL6 и TNF, ассоциированные с ожирением, также способны индуцировать дефекты цилиогенеза ASC $[144,145,152]$. ASC с поврежденными первичными ресничками не способны выполнять свои физиологические функции и вместо этого начинают оказывать провоспалительное действие, секретируя воспалительные цитокины, такие как IL6 и IL8 [144, 152].

Продемонстрирована связь нарушений функций ASC/MSC с развитием легочного фиброза [153-155]. У пациентов с COVID-19, страдающих ожирением, могут развиваться более тяжелые поражения легких с легочным фиброзом вследствие нарушения функций MSC, индуцированного ожирением [131]. Обсуждается возможность использования ASC/MSC в качестве клеточной терапии легочного фиброза и бронхолегочной дисплазии за счет регулирования популяций иммунных клеток в легких, модуляции дифференцировки клеток, в частности фибробластов, и секретирования различных факторов роста $[156,157]$. Эти клетки могут также быть использованы для терапии инфекционных заболеваний из-за их иммуносупрессивных или иммуномодулирующих свойств в зависимости от продукции цитокинов и контекста иммунного ответа [158]. Продолжаются клинические испытания, направленные на оценку эффективности и безопасности ASC/MSC для регулирования иммунной системы, предварительные результаты которых дают основания для оптимизма в отношении использования ASC/MSC в качестве регуляторов пролиферации Т-клеток и взаимодействия с патогенами [159, 160]. Эти клетки обладают антимикробным потенциалом [101], что подчеркивает значимость ASC/MSC в патогенезе инфекционных заболеваний, а также возможность их применения в качестве новой клеточной терапии для пациентов с COVID-19 с ожирением.

\section{ЗАКЛЮЧЕНИЕ}

В результате проведенных клинико-генетических исследований к настоящему времени накоплен значительный объем данных о синдромальных и несиндромальных формах ожирения. Получено подтверждение участия генов, кодирующих компоненты лептин-меланокортинового пути, в развитии моногенных и полигенных форм ожирения. Имеются сведения о вовлеченности кишечного микробиома в развитие ожирения и его эволюции после бариатрических вмешательств. С учетом вышеизложенного, дальнейшее изучение проблемы ожирения должно быть направлено на выявление взаимосвязей на уровне патогенетических молекулярных 
механизмов с применением системного комплексного подхода, сочетающего методологию оценки комплекса психологических, клинико-инструментальных, биохимических параметров, вклада генетических факторов и состояния микробиоты. Это позволит идентифицировать потенциальные мишени для лекарственной терапии и создаст предпосылки для разработки персонализированных эффективных подходов в диагностике, лечении и профилактике ожирения.

\section{ДОПОЛНИТЕЛЬНАЯ ИНФОРМАЦИЯ}

Источники финансирования. Поисково-аналитическая работа по подготовке рукописи проведена при финансовой поддержке гранта Лондонского Королевского общества (Royal Society, IEC/R2/181075), мегагранта Правительства Российской Федерации (№075-15-2021-595) и НИР (№ госрегистрации АААА-А16-116020350032-1).

Конфликт интересов. Авторы декларируют отсутствие явных и потенциальных конфликтов интересов, связанных с публикацией настоящей статьи.

Участие авторов. Тимашева Я.Р. - создание концепции и плана статьи, поиск и систематизация материала, анализ литературных данных, написание статьи, создание таблиц и рисунков, оформление списка литературы; Балхиярова Ж.Р. - поиск и систематизация материала, внесение правок в рукопись; Кочетова О.В. - анализ литературных данных, внесение правок в рукопись. Все авторы одобрили финальную версию статьи перед публикацией, выразили согласие нести ответственность за все аспекты работы, подразумевающую надлежащее изучение и решение вопросов, связанных с точностью или добросовестностью любой части работы.

\section{СПИСОК ЛИТЕРАТУРЫ | REFERENCES}

1. World Health Organization. Preventing and Managing the Global Epidemic: Report on a WHO Consultation (WHO Technical Report Series 894). Geneva, Switzerland: World Health Organization; 2000.

2. Kontsevaya A, Shalnova S, Deev A, et al. Overweight and Obesity in the Russian Population: Prevalence in Adults and Association with Socioeconomic Parameters and Cardiovascular Risk Factors. Obes Facts. 2019;12(1):103-114. doi: https://doi.org/10.1159/000493885

3. Hales CM, Carroll MD, Fryar CD, et al. Prevalence of Obesity and Severe Obesity Among Adults: United States, 2017-2018. NCHS Data Brief. 2020;360:1-8

4. Blüher M. Adipose tissue inflammation: a cause or consequence of obesity-related insulin resistance? Clin Sci. 2016;130(18):1603-1614. doi: https://doi.org/10.1042/CS20160005

5. Chooi YC, Ding C, Magkos F. The epidemiology of obesity. Metabolism. 2019;92:6-10. doi: https://doi.org/10.1016/j.metabol.2018.09.005

6. Ladabaum U, Mannalithara A, Myer PA, Singh G. Obesity, Abdominal Obesity, Physical Activity, and Caloric Intake in US Adults: 1988 to 2010. Am J Med. 2014;127(8):717-727.e12. doi: https://doi.org/10.1016/j.amjmed.2014.02.026

7. Swinburn BA, Sacks G, Hall KD, et al. The global obesity pandemic: shaped by global drivers and local environments. Lancet. 2011;378(9793):804-814 doi: https://doi.org/10.1016/S0140-6736(11)60813-1

8. Katzmarzyk PT, Pérusse L, Rao D, et al. Familial risk of overweight and obesity in the Canadian population using the WHO/NIH criteria. Obesity research. 2000;8(2):194-197. doi: https://doi.org/10.1038/oby.2000.21

9. Koeppen-Schomerus G, Wardle J, Plomin R. A genetic analysis of weight and overweight in 4-year-old twin pairs. International Journal of Obesity. 2001;25(6):838-844. doi: https://doi.org/10.1038/sj.ijo.0801589

10. Pietiläinen $\mathrm{KH}$, Kaprio J, Rissanen A, et al. Distribution and heritability of BMI in Finnish adolescents aged $16 \mathrm{y}$ and $17 \mathrm{y}$ : A study of 4884 twins and 2509 singletons. International Journal of Obesity. 1999;23(2):107-115. doi: https://doi.org/10.1038/sj.ijo.0800767

11. Allison DB, Kaprio J, Korkeila M, et al. The heritability of body mass index among an international sample of monozygotic twins reared apart. International Journal of Obesity. 1996;20(6):501-506.

12. Feinleib M, Garrison RJ, Fabsitz R, et al. The NHLBI twin study of cardiovascular disease risk factors: methodology and summary of results. Am J Epidemiol. 1977;106(4):284-285 doi: https://doi.org/10.1093/oxfordjournals.aje.a112464

13. Stunkard AJ, Foch TT, Hrubec Z. A twin study of human obesity. JAMA. 1986;256(1):51-54. doi: https://doi.org/10.1001/jama.1986.03380010055024

14. Stunkard AJ, Harris JR, Pedersen NL, et al. The BodyMass Index of Twins Who Have Been Reared Apart. New England Journal of Medicine. 1990;322(21):1483-1487. doi: https://doi.org/10.1056/Nejm199005243222102

15. Fesinmeyer MD, North KE, Ritchie MD, et al. Genetic Risk Factors for BMI and Obesity in an Ethnically Diverse Population: Results from the Population Architecture Using Genomics and Epidemiology (PAGE) Study. Obesity. 2013;21(4):835-846. doi: https://doi.org/10.1002/oby.20268
16. Rohde K, Keller M, la Cour Poulsen L, et al. Genetics and epigenetics in obesity. Metabolism. 2019;92:37-50. doi: https://doi.org/10.1016/j.metabol.2018.10.007

17. Singh RK, Kumar P, Mahalingam K. Molecular genetics of human obesity: A comprehensive review. CR Biol. 2017;340(2):87-108. doi: https://doi.org/10.1016/j.crvi.2016.11.007

18. Kaur Y, de Souza RJ, Gibson WT, et al. A systematic review of genetic syndromes with obesity. Obes Rev. 2017;18(6):603-634. doi: https://doi.org/10.1111/obr.12531

19. Forsythe E, Kenny J, Bacchelli C, Beales PL. Managing BardetBiedl Syndrome - Now and in the Future. Front Pediatr. 2018;6. doi: https://doi.org/10.3389/fped.2018.00023

20. Bonnefond A, Raimondo A, Stutzmann F, et al. Loss-of-function mutations in SIM1 contribute to obesity and Prader-Willi-like features. The Journal of clinical investigation. 2013;123(7):3037-3041. doi: https://doi.org/10.1172/JCl68035

21. Desch L, Marle N, Mosca-Boidron A-L, et al. 6q16.3q23.3 duplication associated with Prader-Willi-like syndrome. Mol Cytogenet. 2015;8(1):42. doi: https://doi.org/10.1186/s13039-015-0151-6

22. Martinez-Cerdeno V, Lechpammer M, Noctor S, et al. FMR1 premutation with Prader-Willi phenotype and fragile $X$-associated tremor/ataxia syndrome. Clin Case Rep. 2017;5(5):625-629. doi: https://doi.org/10.1002/ccr3.834

23. Pigeyre M, Yazdi FT, Kaur Y, et al. Recent progress in genetics, epigenetics and metagenomics unveils the pathophysiology of human obesity. Clin Sci (Lond). 2016;130(12):943-986. doi: https://doi.org/10.1042/CS20160136

24. Saeed S, Arslan M, Froguel P. Genetics of Obesity in Consanguineous Populations: Toward Precision Medicine and the Discovery of Novel Obesity Genes. Obesity (Silver Spring). 2018;26(3):474-484. doi: https://doi.org/10.1002/oby.22064

25. Ingelsson E, McCarthy MI. Human Genetics of Obesity and Type 2 Diabetes Mellitus: Past, Present, and Future. Circ Genom Precis Med. 2018;1 1(6):e002090 doi: https://doi.org/10.1161/CIRCGEN.118.002090

26. Choquet $\mathrm{H}$, Meyre D. Molecular basis of obesity: current status and future prospects. Curr Genomics. 2011;12(3):154-168. doi: https://doi.org/10.2174/138920211795677921

27. Huvenne H, Dubern B, Clement K, et al. Rare Genetic Forms of Obesity: Clinical Approach and Current Treatments in 2016. Obes Facts. 2016;9(3):158-173. doi: https://doi.org/10.1159/000445061

28. Zhang Y, Proenca R, Maffei M, et al. Positional cloning of the mouse obese gene and its human homologue. Nature. 1994;372(6505):425-432. doi: https://doi.org/10.1038/372425a0

29. Morton GJ, Meek TH, Schwartz MW. Neurobiology of food intake in health and disease. Nat Rev Neurosci. 2014;15(6):367-378. doi: https://doi.org/10.1038/nrn3745

30. Licinio J, Caglayan S, Ozata M, et al. Phenotypic effects of leptin replacement on morbid obesity, diabetes mellitus, hypogonadism, and behavior in leptin-deficient adults. Proc Natl Acad Sci U SA. 2004;101(13):4531-4536. doi: https://doi.org/10.1073/pnas.0308767101

31. Farooqi IS, Keogh JM, Yeo GS, et al. Clinical spectrum of obesity and mutations in the melanocortin 4 receptor gene. N Engl J Med. 2003;348(12):1085-1095. doi: https://doi.org/10.1056/NEJMoa022050 
32. Krude H, Biebermann $\mathrm{H}$, Luck W, et al. Severe early-onset obesity, adrenal insufficiency and red hair pigmentation caused by POMC mutations in humans. Nat Genet. 1998;19(2):155-157. doi: https://doi.org/10.1038/509

33. Vaisse C, Clement K, Durand E, et al. Melanocortin-4 receptor mutations are a frequent and heterogeneous cause of morbid obesity. J Clin Invest. 2000;106(2):253-262 doi: https://doi.org/10.1172/JCI9238

34. Pritchard LE, Turnbull AV, White A. Pro-opiomelanocortin processing in the hypothalamus: impact on melanocortin signalling and obesity. J Endocrinol. 2002;172(3):411-421. doi: https://doi.org/10.1677/joe.0.1720411

35. O'Rahilly S, Gray H, Humphreys PJ, et al. Brief report: impaired processing of prohormones associated with abnormalities of glucose homeostasis and adrenal function. NEngl J Med. 1995;333(21):1386-1390. doi: https://doi.org/10.1056/NEJM199511233332104

36. Jackson RS, Creemers JW, Ohagi S, et al. Obesity and impaired prohormone processing associated with mutations in the human prohormone convertase 1 gene. Nat Genet. 1997;16(3):303-306. doi: https://doi.org/10.1038/ng0797-303

37. Saeed S, Bonnefond A, Tamanini F, et al. Loss-of-function mutations in ADCY3 cause monogenic severe obesity. Nature Genetics. 2018;50(2):175-179. doi: https://doi.org/10.1038/s41588-017-0023-6

38. Grarup N, Moltke I, Andersen MK, et al. Loss-of-function variants in ADCY3 increase risk of obesity and type 2 diabetes. Nat Genet. 2018;50(2):172-174. doi: https://doi.org/10.1038/s41588-017-0022-7

39. Ramachandrappa S, Raimondo A, Cali AM, et al. Rare variants in single-minded 1 (SIM1) are associated with severe obesity. J Clin Invest. 2013;123(7):3042-3050. doi: https://doi.org/10.1172/JCI68016

40. Holder JL Jr, Butte NF, Zinn AR. Profound obesity associated with a balanced translocation that disrupts the SIM1 gene. Human molecular genetics. 2000;9(1):101-108. doi: https://doi.org/10.1093/hmg/9.1.101

41. Chan LF, Webb TR, Chung TT, et al. MRAP and MRAP2 are bidirectional regulators of the melanocortin receptor family. Proc Natl Acad Sci U S A. 2009;106(15):6146-6151. doi: https://doi.org/10.1073/pnas.0809918106

42. Baron M, Maillet J, Huyvaert M, et al. Loss-of-function mutations in MRAP2 are pathogenic in hyperphagic obesity with hyperglycemia and hypertension. Nat Med. 2019;25(11):1733-1738. doi: https://doi.org/10.1038/s41591-019-0622-0

43. Sebag JA, Zhang C, Hinkle PM, et al. Developmental control of the melanocortin-4 receptor by MRAP2 proteins in zebrafish. Science. 2013;341 (6143):278-281. doi: https://doi.org/10.1126/science.1232995

44. Baron $M$, Froguel $P$, Bonnefond $A$. Du nouveau dans la génétique des formes monogéniques d'obésité et son impact pour mieux en comprendre la physiopathologie. Med Sci (Paris). 2020;36(10):859-865. doi: https://doi.org/10.1051/medsci/2020156

45. Yeo GS, Connie Hung CC, Rochford J, et al. A de novo mutation affecting human TrkB associated with severe obesity and developmental delay. Nat Neurosci. 2004;7(11):1187-1189. doi: https://doi.org/10.1038/nn1336

46. Gray J, Yeo GS, Cox JJ, et al. Hyperphagia, severe obesity, impaired cognitive function, and hyperactivity associated with functional loss of one copy of the brain-derived neurotrophic factor (BDNF) gene. Diabetes. 2006;55(12):3366-3371. doi: https://doi.org/10.2337/db06-0550

47. Yengo L, Sidorenko J, Kemper KE, et al. Meta-analysis of genome-wide association studies for height and body mass index in $\sim 700000$ individuals of European ancestry. Human molecular genetics. 2018;27(20):3641-3649. doi: https://doi.org/10.1093/hmg/ddy271

48. Tyrrell J, Wood AR, Ames RM, et al. Gene-obesogenic environment interactions in the UK Biobank study. International Journal of Epidemiology. 2017:46(2):559-575. doi: https://doi.org/10.1093/ije/dyw337

49. Goodarzi MO. Genetics of obesity: what genetic association studies have taught us about the biology of obesity and its complications. Lancet Diabetes \& Endocrinology. 2018;6(3):223-236. doi: https://doi.org/10.1016/S2213-8587(17)30200-0

50. Barres R, Kirchner H, Rasmussen M, et al. Weight loss after gastric bypass surgery in human obesity remodels promoter methylation. Cell Rep. 2013;3(4):1020-1027. doi: https://doi.org/10.1016/j.celrep.2013.03.018
51. Keller M, Hopp L, Liu X, et al. Genome-wide DNA promoter methylation and transcriptome analysis in human adipose tissue unravels novel candidate genes for obesity. Mol Metab. 2017;6(1):86-100. doi: https://doi.org/10.1016/.j.molmet.2016.11.003

52. Nilsson E, Jansson PA, Perfilyev A, et al. Altered DNA methylation and differential expression of genes influencing metabolism and inflammation in adipose tissue from subjects with type 2 diabetes. Diabetes. 2014;63(9):2962-2976. doi: https://doi.org/10.2337/db13-1459

53. Wahl S, Drong A, Lehne B, et al. Epigenome-wide association study of body mass index, and the adverse outcomes of adiposity. Nature. 2017;541 (7635):81-86. doi: https://doi.org/10.1038/nature20784

54. Su L.-N, Wang Y-B, Wnag C-G, et al. Network analysis identifies common genes associated with obesity in six obesity-related diseases. Journal of Zhejiang University-SCIENCE B. 2017;18(8):727-732. doi: https://doi.org/10.1631/jzus.B1600454

55. Benzinou M, Creemers JW, Choquet H, et al. Common nonsynonymous variants in PCSK1 confer risk of obesity. Nature genetics. 2008;40(8):943. doi: https://doi.org/10.1038/ng.177

56. Choquet H, Kasberger J, Hamidovic A, et al. Contribution of common PCSK1 genetic variants to obesity in 8,359 subjects from multi-ethnic American population. PLoS One. 2013;8(2):e57857. doi: https://doi.org/10.1371/journal.pone.0057857

57. Rouskas K, Kouvatsi A, Paletas K, et al. Common variants in FTO, MC4R, TMEM18, PRL, AIF1, and PCSK1 show evidence of association with adult obesity in the Greek population. Obesity. 2012;20(2):389-395. doi: https://doi.org/10.1038/oby.2011.177

58. Loos RJ, Lindgren CM, Li S, et al. Common variants near MC4R are associated with fat mass, weight and risk of obesity. Nat Genet. 2008;40(6):768-775. doi: https://doi.org/10.1038/ng.140

59. Claussnitzer M, Dankel SN, Kim KH, et al. FTO obesity variant circuitry and adipocyte browning in humans. New England Journal of Medicine. 2015;373(10):895-907. doi: https://doi.org/10.1056/NEJMoa1502214

60. Smemo S, Tena JJ, Kim K-H, et al. Obesity-associated variants within FTO form long-range functional connections with IRX3. Nature. 2014;507(7492):371-375. doi: https://doi.org/10.1038/nature13138

61. Lilenfeld LR, Kaye WH, Greeno CG, et al. A controlled family study of anorexia nervosa and bulimia nervosa: psychiatric disorders in first-degree relatives and effects of proband comorbidity. Arch Gen Psychiatry. 1998;55(7):603-610. doi: https://doi.org/10.1001/archpsyc.55.7.603

62. Strober M, Freeman R, Lampert C, et al. Controlled family study of anorexia nervosa and bulimia nervosa: evidence of shared liability and transmission of partial syndromes. Am J Psychiatry. 2000;157(3):393-401. doi: https://doi.org/10.1176/appi.ajp.157.3.393

63. Thornton LM, Mazzeo SE, Bulik CM. The Heritability of Eating Disorders: Methods and Current Findings. In: Current Topics in Behavioral Neurosciences. ; 2010:141-156. doi: https://doi.org/10.1007/7854_2010_91

64. Elks CE, den Hoed M, Zhao JH, et al. Variability in the heritability of body mass index: a systematic review and meta-regression. Front Endocrinol (Lausanne). 2012;3:29. doi: https://doi.org/10.3389/fendo.2012.00029

65. Kendler KS, MacLean C, Neale M, et al. The genetic epidemiology of bulimia nervosa. American Journal of Psychiatry. 1991;148(12):1627-1637. doi: https://doi.org/10.1176/ajp.148.12.1627

66. Llewellyn C, Wardle J, Behavioral susceptibility to obesity: gene - environment interplay in the development of weight. Physiology \& Behavior. 2015;152:494-501. doi: https://doi.org/10.1016/j.physbeh.2015.07.006

67. Llewellyn CH, Fildes A, Behavioural Susceptibility Theory: Professor Jane Wardle and the Role of Appetite in Genetic Risk of Obesity. Curr Obes Rep. 2017:6(1):38-45 doi: https://doi.org/10.1007/s13679-017-0247-x

68. Herle M, Smith AD, Kininmonth A, Llewellyn C. The Role of Eating Behaviours in Genetic Susceptibility to Obesity. Curr Obes Rep. 2020;9(4):512-521. doi: https://doi.org/10.1007/s13679-020-00402-0

69. Nicoletti CF, Delfino HBP, Ferreira FC, et al. Role of eating disorders-related polymorphisms in obesity pathophysiology. Rev Endocr Metab Disord. 2019;20(1):115-125. doi: https://doi.org/10.1007/s11154-019-09489-w

70. Masip G, Silventoinen K, Keski-Rahkonen A, et al. The genetic architecture of the association between eating behaviors and obesity: combining genetic twin modeling and polygenic risk scores. Am J Clin Nutr. 2020;112(4):956-966. doi: https://doi.org/10.1093/ajcn/nqaa181 
71. Locke AE, Kahali B, Berndt SI, et al. Genetic studies of body mass index yield new insights for obesity biology. Nature. 2015:518(7538):197-401. doi: https://doi.org/10.1038/nature14177

72. Timshel PN, Thompson JJ, Pers TH. Genetic mapping of etiologic brain cell types for obesity. Elife. 2020;9:e55851. doi: https://doi.org/10.7554/eLife.55851

73. Wabitsch M, Funcke JB, Lennerz B, et al. Biologically inactive leptin and early-onset extreme obesity. N Engl J Med. 2015;372(1):48-54. doi: https://doi.org/10.1056/NEJMoa1406653

74. Santos JL, Cortés VA. Eating behaviour in contrasting adiposity phenotypes: Monogenic obesity and congenital generalized lipodystrophy. Obes Rev. 2021;22(1). doi: https://doi.org/10.1111/obr.13114

75. Paz-Filho G, Mastronardi CA, Licinio J. Leptin treatment: facts and expectations. Metabolism. 2015;64(1):146-156. doi: https://doi.org/10.1016/j.metabol.2014.07.014

76. LuX-Y. The leptin hypothesis of depression: a potential link between mood disorders and obesity? Current opinion in pharmacology. 2007;7(6):648-652. doi: https://doi.org/10.1016/j.coph.2007.10.010

77. Domingos Al, Vaynshteyn J, Voss HU, et al. Leptin regulates the reward value of nutrient. Nature Neuroscience. 2011;14(12):1562-1568. doi: https://doi.org/10.1038/nn.2977

78. Yoshida R, Noguchi K, Shigemura N, et al. Leptin Suppresses Mouse Taste Cell Responses to Sweet Compounds. Diabetes. 2015;64(11):3751-3762. doi: https://doi.org/10.2337/db14-1462

79. Rohde K, Keller M, Horstmann A, et al. Role of genetic variants in ADIPOQ in human eating behavior. Genes \& Nutrition. 2014;10(1):1. doi: https://doi.org/10.1007/s12263-014-0449-8

80. Ma W, Huang T, Heianza Y, et al. Genetic Variations of Circulating Adiponectin Levels Modulate Changes in Appetite in Response to Weight-Loss Diets. J Clin Endocrinol Metab. 2017;102(1):316-325. doi: https://doi.org/10.1210/jc.2016-2909

81. Khalil RB, El Hachem C. Adiponectin in eating disorders. Eat Weight Disord. 2014;19(1):3-10. doi: https://doi.org/10.1007/s40519-013-0094-z

82. Kubota N, Yano W, Kubota T, et al. Adiponectin stimulates AMP-activated protein kinase in the hypothalamus and increases food intake. Cell Metab. 2007;6(1):55-68. doi: https://doi.org/10.1016/j.cmet.2007.06.003

83. Bravo C, Cataldo LR, Galgani J, et al. Leptin/Adiponectin Ratios Using Either Total Or High-Molecular-Weight Adiponectin as Biomarkers of Systemic Insulin Sensitivity in Normoglycemic Women. J Diabetes Res. 2017;2017:1-11. doi: https://doi.org/10.1155/2017/9031079

84. Vasseur F, Meyre D, Froguel P. Adiponectin, type 2 diabetes and the metabolic syndrome: lessons from human genetic studies. Expert Rev Mol Med. 2006;8(27):1-12. doi: https://doi.org/10.1017/S1462399406000147

85. Savage DC. Microbial ecology of the gastrointestinal tract. Annual review of microbiology. 1977;31(1):107-133. doi: https://doi.org/10.1146/annurev.mi.31.100177.000543

86. Tseng $\mathrm{C}-\mathrm{H}, \mathrm{Wu} \mathrm{C}-\mathrm{Y}$. The gut microbiome in obesity. Journal of the Formosan Medical Association. 2019;118:S3-S9. doi: https://doi.org/10.1016/j.jma.2018.07.009

87. Sender R, Fuchs S, Milo R. Are We Really Vastly Outnumbered? Revisiting the Ratio of Bacterial to Host Cells in Humans. Cell. 2016;164(3):337-340. doi: https://doi.org/10.1016/j.cell.2016.01.013

88. Krautkramer KA, Fan J, Bäckhed F. Gut microbial metabolites as multi-kingdom intermediates. Nature Reviews Microbiology. 2021;19(2):77-94. doi: https://doi.org/10.1038/s41579-020-0438-4

89. Meijnikman AS, Gerdes VE, Nieuwdorp M, et al. Evaluating Causality of Gut Microbiota in Obesity and Diabetes in Humans. Endocrine Reviews. 2018;39(2):133-153. doi: https://doi.org/10.1210/er.2017-00192

90. Ley RE, Turnbaugh PJ, Klein S, et al. Human gut microbes associated with obesity. Nature. 2006;444(7122):1022-1023. doi: https://doi.org/10.1038/4441022a

91. Zhao L. The gut microbiota and obesity: from correlation to causality. Nature Reviews Microbiology. 2013;11(9):639-647. doi: https://doi.org/10.1038/nrmicro3089

92. Turnbaugh PJ, Hamady M, Yatsunenko T, et al. A core gut microbiome in obese and lean twins. Nature. 2009;457(7228):480-484. doi: https://doi.org/10.1038/nature07540

93. Bäckhed F, Ding H, Wang T, et al. The gut microbiota as an environmental factor that regulates fat storage. Proceedings of the National Academy of Sciences. 2004;101(44):15718-15723. doi: https://doi.org/10.1073/pnas.0407076101
94. Ley RE, Bäckhed F, Turnbaugh P, et al. Obesity alters gut microbial ecology. Proceedings of the National Academy of Sciences. 2005;102(31):11070-11075. doi: https://doi.org/10.1073/pnas.0504978102

95. Turnbaugh PJ, Ley RE, Mahowald MA, et al. An obesity-associated gut microbiome with increased capacity for energy harvest. Nature. 2006:444(7122):1027. doi: https://doi.org/10.1038/nature05414

96. Turpin W, Espin-Garcia O, Xu W, et al. Association of host genome with intestinal microbial composition in a large healthy cohort. Nature Genetics. 2016;48(11):1413-1417. doi: https://doi.org/10.1038/ng.3693

97. Goodrich Julia K, Waters Jillian L, Poole Angela C, et al. Human Genetics Shape the Gut Microbiome. Cell. 2014;159(4):789-799. doi: https://doi.org/https://doi.org/10.1016/j.cell.2014.09.053

98. Bonder MJ, Kurilshikov A, Tigchelaar EF, et al. The effect of host genetics on the gut microbiome. Nat Genet. 2016;48(11):1407-1412. doi: https://doi.org/10.1038/ng.3663

99. Crost EH, Le Gall G, Laverde-Gomez JA, et al. Mechanistic Insights Into the Cross-Feeding of Ruminococcus gnavus and Ruminococcus bromii on Host and Dietary Carbohydrates. Front Microbiol. 2018:9:2558. doi: https://doi.org/10.3389/fmicb.2018.02558

100. Kurilshikov A, Medina-Gomez C, Bacigalupe R, et al. Large-scale association analyses identify host factors influencing human gut microbiome composition. Nat Genet. 2021;53(2):156-165. doi: https://doi.org/10.1038/s41588-020-00763-1

101. Yoshii K, Hosomi K, Sawane K, et al. Metabolism of Dietary and Microbial Vitamin B Family in the Regulation of Host Immunity. Front Nutr. 2019;6:48. doi: https://doi.org/10.3389/fnut.2019.00048

102. Rowley CA, Kendall MM. To B12 or not to B12: Five questions on the role of cobalamin in host-microbial interactions. PLoS pathogens. 2019;15(1):e1007479-e1007479. doi: https://doi.org/10.1371/journal.ppat.1007479

103. Rung J, Cauchi S, Albrechtsen A, et al. Genetic variant nea IRS1 is associated with type 2 diabetes, insulin resistance and hyperinsulinemia. Nat Genet. 2009;41(10):1110-1115. doi: https://doi.org/10.1038/ng.443

104. Liu TC, Kern JT, Jain U, et al. Western diet induces Paneth cell defects through microbiome alterations and farnesoid $X$ receptor and type I interferon activation. Cell Host Microbe. 2021;29(6):988-1001. doi: https://doi.org/10.1016/j.chom.2021.04.004

105. Zhang H, DiBaise JK, Zuccolo A, et al. Human gut microbiota in obesity and after gastric bypass. Proceedings of the National Academy of Sciences. 2009;106(7):2365-2370. doi: https://doi.org/10.1073/pnas.0812600106

106. Aron-Wisnewsky J, Prifti E, Belda E, et al. Major microbiota dysbiosis in severe obesity: fate after bariatric surgery. Gut. 2019;68(1):70. doi: https://doi.org/10.1136/gutjnl-2018-316103

107. West KA, Kanu C, Maric T, et al. Longitudinal metabolic and gut bacterial profiling of pregnant women with previous bariatric surgery. Gut. 2020;69(8):1452-1459. doi: https://doi.org/10.1136/gutjnl-2019-319620

108. Davies N, O'Sullivan JM, Plank LD, et al. Gut Microbial Predictors of Type 2 Diabetes Remission Following Bariatric Surgery. Obes Surg 2020;30(9):3536-3548. doi: https://doi.org/10.1007/s1 1695-020-04684-0

109. Mabey JG, Chaston JM, Castro DG, et al. Gut microbiota differs a decade after bariatric surgery relative to a nonsurgical comparison group. Surg Obes Relat Dis. 2020;16(9):1304-1311. doi: https://doi.org/10.1016/j.soard.2020.04.006

110. Ilhan ZE, DiBaise JK, Dautel SE, et al. Temporospatial shifts in the human gut microbiome and metabolome after gastric bypass surgery. npj Biofilms Microbiomes. 2020;6(1):12. doi: https://doi.org/10.1038/s41522-020-0122-5

111. Palaiodimos L, Kokkinidis DG, Li W, et al. Severe obesity, increasing age and male sex are independently associated with worse inhospital outcomes, and higher in-hospital mortality, in a cohort of patients with COVID-19 in the Bronx, New York. Metabolism. 2020;108:154262. doi: https://doi.org/10.1016/j.metabol.2020.154262

112. Petrilli CM, Jones SA, Yang J, et al. Factors associated with hospital admission and critical illness among 5279 people with coronavirus disease 2019 in New York City: prospective cohort study. BMJ. 2020;369:m1966. doi: https://doi.org/10.1136/bmj.m1966

113. Kalligeros M, Shehadeh F, Mylona EK, et al. Association of Obesity with Disease Severity Among Patients with Coronavirus Disease 2019. Obesity (Silver Spring). 2020;28(7):1200-1204. doi: https://doi.org/10.1002/oby.22859 
114. Simonnet A, Chetboun M, Poissy J, et al. High Prevalence of Obesity in Severe Acute Respiratory Syndrome Coronavirus-2 (SARS-CoV-2) Requiring Invasive Mechanical Ventilation. Obesity (Silver Spring). 2020;28(7):1195-1199. doi: https://doi.org/10.1002/oby.22831

115. Hur K, Price CPE, Gray EL, et al. Factors Associated With Intubation and Prolonged Intubation in Hospitalized Patients With COVID-19. Otolaryngol Head Neck Surg. 2020;163(1):170-178. doi: https://doi.org/10.1177/0194599820929640

116. Tartof SY, Qian L, Hong V, et al. Obesity and Mortality Among Patients Diagnosed With COVID-19: Results From an Integrated Health Care Organization. Ann Intern Med. 2020;173(10):773-781. doi: https://doi.org/10.7326/M20-3742

117. Ko JY, Danielson ML, Town M, et al. Risk Factors for Coronavirus Disease 2019 (COVID-19)-Associated Hospitalization: COVID-19Associated Hospitalization Surveillance Network and Behavioral Risk Factor Surveillance System. Clin Infect Dis. 2021;72(11):e695-e703. doi: https://doi.org/10.1093/cid/ciaa1419

118. Zhu Z, Hasegawa K, Ma B, Fujiogi M, Camargo CA, Liang L. Association of obesity and its genetic predisposition with the risk of severe COVID-19: Analysis of population-based cohort data. Metabolism. 2020;112:154345. doi: https://doi.org/10.1016/j.metabol.2020.154345

119. Ellinghaus D, Degenhardt F, Bujanda L, et al. Genomewide Association Study of Severe Covid-19 with Respiratory Failure. N Engl J Med. 2020;383(16):1522-1534. doi: https://doi.org/10.1056/NEJMoa2020283

120. Shelton JF, Shastri AJ, Ye C, et al. Trans-ancestry analysis reveals genetic and nongenetic associations with COVID-19 susceptibility and severity. Nature Genetics. 2021;53(6):801-808. doi: https://doi.org/10.1038/s41588-021-00854-7

121. Pulit SL, Stoneman C, Morris AP, et al. Meta-analysis of genomewide association studies for body fat distribution in 694649 individuals of European ancestry. Hum Mol Genet. 2019;28(1):166-174. doi: https://doi.org/10.1093/hmg/ddy327

122. Dubé M-P, Lemaçon A, Barhdadi A, et al. Genetics of symptom remission in outpatients with COVID-19. Scientific Reports. 2021;11(1):10847. doi: https://doi.org/10.1038/s41598-021-90365-6

123. Roos J, Dahlhaus $M$, Funcke J-B, et al. miR-146a regulates insulin sensitivity via NPR3. Cellular and Molecular Life Sciences. 2021;78(6):2987-3003. doi: https://doi.org/10.1007/s00018-020-03699-1

124. Aung N, Khanji MY, Munroe PB, Petersen SE. Causal Inference for Genetic Obesity, Cardiometabolic Profile and COVID-19 Susceptibility: A Mendelian Randomization Study. Front Genet. 2020;11. doi: https://doi.org/10.3389/fgene.2020.586308

125. Zhou $P$, Yang $X L$, Wang $X G$, et al. A pneumonia outbreak associated with a new coronavirus of probable bat origin. Nature. 2020;579(7798):270273. doi: https://doi.org/10.1038/s41586-020-2012-7

126. Al-Benna S. Association of high level gene expression of ACE2 in adipose tissue with mortality of COVID-19 infection in obese patients. Obes Med. 2020;19:100283 doi: https://doi.org/10.1016/j.obmed.2020.100283

127. Pinheiro T de A, Barcala-Jorge AS, Andrade JMO, et al. Obesity and malnutrition similarly alter the renin-angiotensin system and inflammation in mice and human adipose. J Nutr Biochem. 2017:48(11):74-82. doi: https://doi.org/10.1016/j.jnutbio.2017.06.008

128. Radzikowska U, Ding M, Tan G, et al. Distribution of ACE2, CD147, CD26, and other SARS-CoV-2 associated molecules in tissues and immune cells in health and in asthma, COPD, obesity, hypertension, and COVID-19 risk factors. Allergy. 2020;75(11):2829-2845. doi: https://doi.org/10.1111/all.14429

129. Sell H, Bluher M, Kloting N, et al. Adipose dipeptidyl peptidase-4 and obesity: correlation with insulin resistance and depot-specific release from adipose tissue in vivo and in vitro. Diabetes Care. 2013;36(12):4083-4090. doi: https://doi.org/10.2337/dc13-0496

130. Bassendine MF, Bridge SH, McCaughan GW, Gorrell MD. COVID-19 and comorbidities: A role for dipeptidyl peptidase 4 in disease severity? J Diabetes. 2020;12(9):649-658. doi: https://doi.org/10.1111/1753-0407.13052

131. Ritter A, Kreis NN, Louwen F, et al. Obesity and COVID-19: Molecular Mechanisms Linking Both Pandemics. Int J Mol Sci. 2020;21(16):5793. doi: https://doi.org/10.3390/ijms21165793

132. Yanagimachi T, Fujita $Y$, Takeda Y, et al. Dipeptidyl peptidase-4 inhibitor treatment induces a greater increase in plasma levels of bioactive GIP than GLP-1 in nondiabetic subjects. Molecular Metabolism. 2017;62:226-231. doi: https://doi.org/10.1016/j.molmet.2016.12.009
133. Marques AP, Cunha-Santos J, Leal $H$, et al. Dipeptidyl peptidase IV (DPP-IV) inhibition prevents fibrosis in adipose tissue of obese mice. Biochim Biophys Acta Gen Subj. 2018;1862(3):403-413. doi: https://doi.org/10.1016/j.bbagen.2017.11.012

134. Rohrborn D, Eckel J, Sell H. Shedding of dipeptidy peptidase 4 is mediated by metalloproteases and upregulated by hypoxia in human adipocytes and smooth muscle cells. Febs Letters. 2014;588(21):3870-3877. doi: https://doi.org/10.1016/j.febslet.2014.08.029

135. Gallwitz B. Clinical Use of DPP-4 Inhibitors. Front Endocrinol (Lausanne). 2019;10. doi: https://doi.org/10.3389/fendo.2019.00389

136. Song J, Li Y, Huang $X$, et al. Systematic analysis of ACE2 and TMPRSS2 expression in salivary glands reveals underlying transmission mechanism caused by SARS-CoV-2. J Med Virol. 2020;92(11):2556-2566. doi: https://doi.org/10.1002/jmv.26045

137. Shin K, Pandey A, Liu XQ, et al. Preferential apelin-13 production by the proprotein convertase PCSK3 is implicated in obesity. Febs Open Bio. 2013;3:328-333. doi: https://doi.org/10.1016/j.fob.2013.08.001

138. Cyranoski D. Profile of a killer: the complex biology powering the coronavirus pandemic. Nature. 2020;581(7806):22-26. doi: https://doi.org/10.1038/d41586-020-01315-7

139. Cinti S, Mitchell G, Barbatelli G, et al. Adipocyte death defines macrophage localization and function in adipose tissue of obese mice and humans. J Lipid Res. 2005;46(11):2347-2355. doi: https://doi.org/10.1194/jlr.M500294-JLR200

140. Marques-Vidal $P$, Bastardot F, von Känel $R$, et al. Association between circulating cytokine levels, diabetes and insulin resistance in a population-based sample (CoLaus study). Clin Endocrinol (Oxf). 2013;78(2):232-241. doi: https://doi.org/10.1111/j.1365-2265.2012.04384.x

141. Lockhart SM, O'Rahilly S. When Two Pandemics Meet: Why Is Obesity Associated with Increased COVID-19 Mortality? Med. 2020;1 (1):33-42 doi: https://doi.org/10.1016/j.medj.2020.06.005

142. Kreutz R, Algharably EAE-H, Azizi M, et al. Hypertension, the renin-angiotensin system, and the risk of lower respiratory tract infections and lung injury: implications for COVID-19. Cardiovasc Res. 2020;116(10):1688-1699. doi: https://doi.org/10.1093/cvr/cvaa097

143. Louwen F, Ritter A, Kreis N, et al. Insight into the development of obesity: functional alterations of adipose-derived mesenchymal stem cells. Obesity Reviews. 2018;19(7):888-904 doi: https://doi.org/10.1111/obr.12679

144. Ritter A, Louwen F, Yuan J, Deficient primary cilia in obese adipose-derived mesenchymal stem cells: obesity, a secondary ciliopathy? Obes Rev. 2018;19(10):1317-1328. doi: https://doi.org/10.1111/obr.12716

145. Ritter A, Kreis NN, Roth S, et al. Restoration of primary cilia in obese adipose-derived mesenchymal stem cells by inhibiting Aurora A or extracellular signal-regulated kinase. Stem Cell Res Ther. 2019;10(1)255. doi: https://doi.org/10.1186/s13287-019-1373-z

146. Onate B, Vilahur G, Camino-Lopez S, et al. Stem cells isolated from adipose tissue of obese patients show changes in their transcriptomic profile that indicate loss in stemcellness and increased commitment to an adipocyte-like phenotype. BMC Genomics. 2013;14(1):625. doi: https://doi.org/10.1186/1471-2164-14-625

147. Gealekman O, Guseva N, Hartigan C, et al. Depot-specific differences and insufficient subcutaneous adipose tissue angiogenesis in human obesity. Circulation. 2011;123(2):186-194 doi: https://doi.org/10.1161/CIRCULATIONAHA.110.970145

148. Oñate B, Vilahur G, Ferrer-Lorente R, et al. The subcutaneous adipose tissue reservoir of functionally active stem cells is reduced in obese patients. FASEB J. 2012;26(10):4327-4336 doi: https://doi.org/10.1096/fi.12-207217

149. Serena C, Keiran N, Ceperuelo-Mallafre V, et al. Obesity and Type 2 Diabetes Alters the Immune Properties of Human Adipose Derived Stem Cells. Stem Cells. 2016;34(10):2559-2573. doi: https://doi.org/10.1002/stem.2429

150. Oliva-Olivera W, Gea AL, Lhamyani S, et al. Differences in the Osteogenic Differentiation Capacity of Omenta Adipose-Derived Stem Cells in Obese Patients With and Without Metabolic Syndrome. Endocrinology. 2015;156(12):4492-4501. doi: https://doi.org/10.1210/en.2015-1413

151. Mariani S, Di Rocco G, Toietta G, et al. Sirtuins 1-7 expression in human adipose-derived stem cells from subcutaneous and visceral fat depots: influence of obesity and hypoxia. Endocrine. 2017;57(3):455-463. doi: https://doi.org/10.1007/s12020-016-1170-8 
152. Ritter A, Friemel A, Kreis NN, et al. Primary Cilia Are Dysfunctional in Obese Adipose-Derived Mesenchymal Stem Cells. Stem Cell Reports. 2018;10(2):583-599. doi: https://doi.org/10.1016/j.stemcr.2017.12.022

153. Xie T, Liang J, Liu N, et al. Transcription factor TBX4 regulates myofibroblast accumulation and lung fibrosis. The Journal of clinical investigation. 2016;126(8):3063-3079. doi: https://doi.org/10.1172/JCl85328

154. Kramann R, Schneider RK, DiRocco DP, et al. Perivascular Gli1 + Progenitors Are Key Contributors to Injury-Induced Organ Fibrosis. Cell Stem Cell. 2015;16(1):51-66. doi: https://doi.org/10.1016/.jstem.2014.11.004

155. Marriott S, Baskir RS, Gaskill C, et al. ABCG2 pos lung mesenchymal stem cells are a novel pericyte subpopulation that contributes to fibrotic remodeling. Am J Physiol Physiol. 2014;307(8):C684-C698. doi: https://doi.org/10.1152/ajpcell.00114.2014

156. Chuang H-M, Shih TE, Lu K-Y, et al. Mesenchymal Stem Cell Therapy of Pulmonary Fibrosis. Cell Transplant. 2018;27(11):1581-1587. doi: https://doi.org/10.1177/0963689718787501
157. Simones AA, Beisang DJ, Panoskaltsis-Mortari A, Roberts KD. Mesenchymal stem cells in the pathogenesis and treatment of bronchopulmonary dysplasia: a clinical review. Pediatr Res. 2018;83(1-2):308-317. doi: https://doi.org/10.1038/pr.2017.237

158. Bhattacharya D., Dwivedi V. Understanding the Role of Mesenchymal Stem Cells in Infectious Diseases: Focus on Tuberculosis, Malaria. Sepsis and HIV. Electronic J Biol 2016;12(3).

159. Waldner M, Zhang W, James IB, et al. Characteristics and Immunomodulating Functions of Adipose-Derived and Bone Marrow-Derived Mesenchymal Stem Cells Across Defined Human Leukocyte Antigen Barriers. Front Immunol. 2018;9:1642. doi: https://doi.org/10.3389/fimmu.2018.01642

160. Weiss ARR, Dahlke MH. Immunomodulation by Mesenchymal Stem Cells (MSCs): Mechanisms of Action of Living, Apoptotic, and Dead MSCs. Front Immunol. 2019;10:1191. doi: https://doi.org/10.3389/fimmu.2019.01191

Рукопись получена: 30.06.2021. Одобрена к публикации: 02.08.2021. Опубликована online: 03.09.2021.

\section{ИНФОРМАЦИЯ ОБ АВТОРАХ [AUTHORS INFO]}

*Тимашева Янина Римовна, к.м.н. [Yanina R. Timasheva, MD, PhD]; адрес: Россия, 450054 Уфа, проспект Октября, д. 71; ORCID: https://orcid.org/0000-0002-9918-6962; eLibrary SPIN: 9962-8494; e-mail: ianina_t@mail.ru

Балхиярова Жанна Радиковна, к.M.H. [Zhanna R. Balkhiyarova, MD, PhD]; ORCID: https://orcid.org/0000-0003-3553-7126; eLibrary SPIN: 3176-3244; e-mail: JaNe125@yandex.ru

Кочетова Ольга Владимировна, к.б.н. [Olga V. Kochetova, PhD]; ORCID: https://orcid.org/0000-0002-2944-4428; eLibrary SPIN: 3461-3952. e-mail: ecolab@mail.ru

\section{ЦИТИРОВАТЬ:}

Тимашева Я.Р., Балхиярова Ж.Р., Кочетова О.В. Современное состояние исследований в области ожирения: генетические аспекты, роль микробиома и предрасположенность к COVID-19 // Проблемы эндокринологии. — 2021. — T. 67. — №4. - C. 20-35. doi: https://doi.org/10.14341/probl12775

\section{TO CITE THIS ARTICLE:}

Timasheva YR, Balkhiyarova ZhR, Kochetova OV. Current state of the obesity research: genetic aspects, the role of microbiome, and susceptibility to COVID-19. Problems of Endocrinology. 2021;67(4):20-35. doi: https://doi.org/10.14341/probl12775 